\title{
$\mathrm{KCC} 2$ and autism/epilepsy risk gene products
}

\section{The K-Cl co-transporter 2 is a point of convergence for multiple autism spectrum disorder and epilepsy risk gene products.}

Joshua L. Smalley1, Georgina Kontou1, Catherine Choi1, Qiu Ren1, David Albrecht1, Krithika Abiraman1, Miguel A. Rodriguez Santosı, Christopher E. Bope1, Tarek Z. Deeb1, Paul A. Davies1, Nicholas J. Brandon 2,3 and Stephen J. Moss* ${ }_{1,4}$

1Department of Neuroscience, Tufts University School of Medicine, 136 Harrison Ave, Boston 02111. ${ }_{2}$ Sage Therapeutics, 215 First Street, Cambridge, MA 02142. 3Department of Neuroscience, Physiology, and Pharmacology, University College, London, WC1E, 6BT, UK.

Running Title: KCC2 and autism/epilepsy risk gene products

To whom correspondence should be addressed: Professor. S. J. Moss, Department of Neuroscience, Tufts University School of Medicine, Boston MA 02111, Telephone: (617) 636-3976; FAX: (617) 636-2413; Email: Stephen.Moss@Tufts.edu

Key words; KCC2, epilepsy, proteome, FMRP, autism, phosphorylation.

\begin{abstract}
KCC2 plays a critical role in determining the efficacy of synaptic inhibition and deficits in its activity lead to epilepsy and neurodevelopmental delay. Here we use unbiased proteomic analyses to demonstrate that $\mathrm{KCC} 2$ forms stable protein complexes in the neuronal plasma membrane with 96 autism and/or epilepsy risk gene (ASD/Epi) products including ANKB, ANKG, CNTN1, ITPR1, NCKAP1, SCN2A, SHANK3, SPTAN1, and SPTBN1. Many of these proteins are also targets of Fragile-X mental retardation protein (FMRP), the inactivation of which is the leading monogenic cause of autism. Accordingly, the expression of a subset of these KCC2-binding partners was decreased in Fmr1 knockout mice. Fmr1 knockout compromised KCC2 phosphorylation, a key regulatory mechanism for transporter activity and the postnatal development of GABAergic inhibition. Thus, KCC2 is a point of convergence for multiple ASD/Epi risk genes and therapies targeting this transporter may have broad utility in alleviating these heterogeneous disorders and their associated epilepsies.
\end{abstract}

The $\mathrm{K}_{+} / \mathrm{Cl}$ - co-transporter $\mathrm{KCC} 2$ (encoded by the gene SLC12A5) is the principal $\mathrm{Cl}$-extrusion mechanism employed by mature neurons in the CNS (1). Its activity is a pre-requisite for the efficacy of fast synaptic inhibition mediated by Glycine (GLYR) and type A $\gamma$-aminobutyric acid receptors (GABAAR), which are $\mathrm{Cl}_{-}$permeable ligand-gated ion channels. At prenatal and early postnatal stages in rodents, neurons have elevated intracellular $\mathrm{Cl}_{-}$levels resulting in depolarizing GABAA-mediated currents (2). The postnatal development of canonical hyperpolarizing GABAAR currents is a reflection of the progressive decrease of intraneuronal $\mathrm{Cl}$ - levels that is caused by the upregulation of $\mathrm{KCC} 2$ expression and subsequent activity (3-6). These changes in neuronal $\mathrm{Cl}_{-}$extrusion reflect a sustained increase in the expression levels of KCC2 after birth, the mRNA levels of which do not reach their maximal levels in humans until 20-25 years of age (7). In addition to this, the appropriate developmental appearance of hyperpolarizing $\mathrm{GABA}_{\mathrm{A}} \mathrm{R}$ currents is also in part determined by the phosphorylation status of $\mathrm{KCC} 2$, a process that facilitates its membrane trafficking and surface activity (8-13).

In keeping with its essential role in determining the efficacy of synaptic inhibition, 
$\mathrm{KCC} 2$ and autism/epilepsy risk gene products

humans with mutations in $\mathrm{KCC} 2$ develop severe epilepsy soon after birth (14-16). Deficits in KCC2 activity are also believed to contribute to the development of temporal lobe epilepsy (17, 18 ), in addition to other traumas including ischemia and neuropathic pain $(19,20)$. Given the critical role that $\mathrm{KCC} 2$ plays in determining the maturation of inhibitory neurotransmission, subtle changes in its function are also strongly implicated in autism spectrum disorders (ASD) (21). The most common monogenic cause of ASDs is the inactivation of the fragile $\mathrm{X}$-mental retardation protein (FMRP). Inactivation of FMRP in mice (FMR1 KO), a widely used model of autism, delays the postnatal development of GABAergic inhibition. Likewise, alterations in KCC2 function are associated with Downs syndrome (22), fragile X syndrome (23), and Rett syndrome (24-26).

Accumulating evidence from highthroughput sequencing of patients has identified a divergent list of $>400$ ASD and epilepsy risk genes (ASD/Epi), many of which have been replicated in murine models (27). These genes encode proteins with a broad array of functions, however, the mechanisms by which these heterogenous gene products exert their pathological effects remains ill-defined (28). Here, we isolated stable protein complexes that contain KCC2 from the plasma membrane of mouse forebrain, and characterized their composition using an unbiased proteomic approach. In this way we identified many novel $\mathrm{KCC} 2$-associated proteins. Using bioinformatic analyses we discovered that KCC2 forms stable protein complexes containing many ASD/Epi risk gene products, several of which are classed as 'high-risk' (29). We then demonstrated that a selected cohort of high-risk proteins, including $\mathrm{KCC} 2$ itself, are aberrantly expressed in plasma membrane fractions from FMR1 KO mice, correlating with altered $\mathrm{KCC} 2$ phosphorylation at known and novel sites. Thus, KCC2 is a point of convergence for multiple ASD/Epi risk genes that act in part to regulate its phosphorylation.

\section{Results}


$\mathrm{KCC} 2$ and autism/epilepsy risk gene products

performed with non-immune mouse IgG. An immunoblot of the same sample confirmed that these bands contained $\mathrm{KCC} 2$. Immunoblots of plasma membrane lysates separated by $\mathrm{BN}$ PAGE showed that these distinct KCC2 complex bands exist in the lysate and are not an artifact of or degraded by purification. Despite the high stringency of our method (with high speed centrifugation and low concentration SDS exposure), no monomeric KCC2 was observed $(\sim 150 \mathrm{kDa})$, indicating that $\mathrm{KCC} 2$ was maintained in higher order complexes. This may disrupt low affinity protein interactions and favor the detection of higher affinity binding partners.

After we confirmed that these well resolved bands contained $\mathrm{KCC} 2$, we assessed their KCC2 content by LC-MS/MS following trypsin digestion (Figure 1d). The 300, 600, and $800 \mathrm{kDa}$ bands contained an average of 706, 260, and 74 total peptides for KCC2 respectively, which equated to coverage of $44 \%, 35 \%$, and $23 \%$ respectively. In all three bands, the majority of peptides corresponded to the cytoplasmic and extracellular domains of $\mathrm{KCC} 2$, while peptides corresponding to the transmembrane domains were rarely detected. The failure to detect these regions is consistent with their high hydrophobicity and subsequent low recovery by LC-MS/MS (Figure S2a). We also noted that the 300, 600 and $800 \mathrm{kDa}$ bands contained peptides derived from $\mathrm{KCC} 1$, which were at approximately 6-fold lower levels than those derived from KCC2. Taken together, these results demonstrate our experimental methodology facilitates the isolation of stable high molecular mass protein complexes enriched in $\mathrm{KCC} 2$.

\section{Analyzing the composition of stable protein complexes of KCC2 Having confirmed the veracity of our $\mathrm{KCC} 2$ purifications we investigated which proteins form stable protein complexes with this transporter in the brain. First, we compiled a data matrix of all the proteins and total peptide counts detected by proteomic analysis in each of our samples (Table S1). We compared the average total peptide counts for $\mathrm{KCC} 2$, with the average total peptide counts for all proteins that were detected in our LC-MS/MS}

spectra (Figure 2a). In the 300, 600, and $800 \mathrm{kDa}$ bands, KCC2 was the most abundant protein detected, however the proportion of peptides for KCC2 relative to peptides for all other detected proteins decreased with increasing complex molecular mass, this is likely due to the increased protein complexity of the high molecular weight complexes.

Next, we evaluated the reproducibility of the detected proteins in each of the 4 repeats for each band size (Figure $2 b$ ). The detected proteins for each band size were highly reproducible with only proteins detected in at least 3 repeats taken forward for further analysis as 'robust binding proteins.' Proteins that also were found in control purifications on control $\mathrm{IgG}$ were removed as components of the CRAPome common contaminants found in affinity-MS data $(31,32)$. We then compared these robust binding proteins between the 300,600, and $800 \mathrm{kDa}$ complexes (Figure 2c). There was a high degree of overlap between the 600 and $800 \mathrm{kDa}$ complexes. The $300 \mathrm{kDa}$ complex had considerable overlap with the 600 and $800 \mathrm{kDa}$ complexes, but it also contained many unique proteins. This unique protein pool is likely to be large proteins that have dissociated from KCC2 complexes.

Finally, we used principle component analysis (PCA) to assess the degree of similarity in binding protein patterns between all of the proteomic samples (Figure 2d). PCA identifies variance between samples and expresses the degree of similarity by proximity in a PCA plot. We did this to both assess the reproducibility of the biological replicates and the degree of difference in the binding proteins for each complex. The binding proteins were assembled into a matrix of all repeats and detected proteins along with total peptide counts for each. The data was normalized by z-transformation (Table S2) and the PCA plotted created using the default settings in the ggfortify package (accessed January 2019) in R (33). The datasets clearly separated into biological repeats of the different mass bands. This demonstrates that we have identified a reproducible set of binding proteins for the 300,600, and $800 \mathrm{kDa}$ bands. While there is a substantial degree of overlap between the interacting proteins from each molecular mass 
KCC2 and autism/epilepsy risk gene products

band, their protein content is different enough that they can be clearly differentiated by PCA. Due to the high number of KCC2 peptides, the degree of unique proteins, and the potential for unbound proteins being present at $300 \mathrm{kDa}$, we only investigated the 600 and $800 \mathrm{kDa}$ bands further for KCC2 associated proteins.

We subjected the top 150 proteins associated with KCC2 in the 600 and $800 \mathrm{kDa}$ bands to network analysis in order to investigate the known protein interactions within each cohort. This was carried out using data from StringDB for previously described experimental interactions (34). We also carried out Gene Ontology (GO) analysis to determine the most overrepresented biological process terms (34). In this way we were able to visualize $\mathrm{KCC} 2$ networks and subnetworks along with developing insights into the functional groups of proteins that associate with KCC2 (Figure 3a and b). Both the 600 and $800 \mathrm{kDa}$ protein groups contained subnetworks of proteins associated with endocytosis (AP2A1, SNAP91, SNAP25, and AAK1), cellular localization (SPTAN1, SPTBN1, ANK2, ANK3, and MYO5A) and ion transport (ATP1A1, ATP1A2, ATP2A2, and ITPR1). Critically, association with the $\mathrm{Na}+\mathrm{K}_{+}$ ATPase alpha subunits supports previous findings in human expression patterns of the concurrent developmental upregulation of both transporters (7). The $800 \mathrm{kDa}$ complex also contained a prominent subnetwork of proteins associated with synaptic signaling and organization (GABBR1, GABBR2, GRM2, and GRM3). Importantly, the GABAB receptor has previously been demonstrated to interact with KCC2 directly (35), which further substantiates our findings. For approximately half of the proteins in both the 600 and $800 \mathrm{kDa}$ complexes, there were no known interactors other than $\mathrm{KCC} 2$.

KCC2 is associated with multiple ASD/Epi risk genes, that are targets for FMR1 As altered KCC2 function has been implicated in ASD and epilepsy, we compiled a list of ASDand epilepsy-associated genes from SFARI (FMRP targets) (36), and EpilepsyGene (37) (Table S5). We compared this list with the top $150 \mathrm{KCC} 2$-associated proteins in both the 600 and $800 \mathrm{kDa}$ bands. We noted that a number of proteins implicated in either ASD or epilepsy or both co-purified with $\mathrm{KCC} 2$ from brain plasma membranes (Figure 4a and b). These comprised several of the highest risk genes associated with autism identified by SFARI, including ANK2, SCN2A (also a major cause of Dravet syndrome) (38), and SHANK3. They also included several products of genes with lower SFARI risk scores, including NCAKP1, MYO5A, ANK3, CACNA1E, CYFIP1, ITPR1 and GPHN, several of which are also highly implicated in various forms of epilepsy. In the $600 \mathrm{kDa}$ complex, 77 out of 150 proteins were ASD/Epi gene products. In the $800 \mathrm{kDa}$ complex this increased to 90 out of 150 . In both the 600 and $800 \mathrm{kDa}$ complexes, there are small subnetworks of known interactions between the associated proteins involved in endocytosis and cellular location but for the majority of proteins, $\mathrm{KCC} 2$ is the only common factor.

Next, we set out to confirm that a cohort of high-risk ASD/Epi gene products coimmunoprecipitated in high molecular weight complexes with KCC2 (Figure 5). These proteins were selected by a combination of total peptide hits detected, SFARI risk score, and implication in epilepsy. We immunoblotted isolated $\mathrm{KCC} 2$ protein complexes resolved by BN-PAGE for ANK2, ANK3, CNTN1, ITPR1, NCKAP1, SCN2A, SHANK3, SPTAN1, and SPTBN1. No immunoreactivity was observed in the control lanes, whereas the high molecular weight protein complexes of $\mathrm{KCC} 2$ showed varying immunoreactivity for all 8 proteins. ANK2, ANK3 (antibody immunoreactive with all splice variants) and NCKAP1 showed specificity for the $600 \mathrm{kDa}$ complex, whereas ITPR1, SCN2A and SPTBN1 showed specificity for the $800 \mathrm{kDa}$ complex. SPTAN1 was equally distributed in the 600 and $800 \mathrm{kDa}$ bands. Only CNTN1 showed positive immunoreactivity for the $300 \mathrm{kDa}$ band. This further demonstrates the specificity of the interactors for high molecular weight KCC2containing protein complexes. KCC2 co-localizes with multiple ASD/Epi
proteins on, or close to the neuronal plasma 
membrane Having established that $\mathrm{KCC} 2$ forms protein complexes with several ASD/Epi risk gene products, we used immunocytochemistry to investigate the proximity of each ASD/Epi risk gene product to KCC2. We used DIV21 mouse primary cultured cortical/hippocampal neurons infected with CamkII-AAV-GFP to ensure we imaged excitatory neurons and to visualize the morphology of the cell and identify whether the interaction between $\mathrm{KCC} 2$ and ASD/Epi risk gene products is restricted to specific cellular compartments (Figure 6a and b). SCN2A, ANK3 and NCKAP1 showed punctate staining along dendrites with extensive colocalization with $\mathrm{KCC} 2$. This was also evident in the fluorescent density plots by the presence of overlapping peaks. ANKB, CNTN1, ITPR1, and SHANK3 exhibited punctate dendritic staining patterns immediately adjacent to KCC2 puncta. SPTAN1, and SPTBN1 were present in large dendritic clusters with KCC2 mostly located on the edges. Taken together, these data demonstrate that proteins associated in high molecular weight complexes with $\mathrm{KCC} 2$ are also highly colocalized with $\mathrm{KCC} 2$ in neurons.

\section{Inactivation of Fmr1 reduces the expression of KCC2 and subset of ASD/Epi gene products} We noted that many of the proteins associated with KCC2 are targets for mental retardation protein (FMRP), the mutation of which is the leading monogenic cause of autism. FMRP is an RNA binding protein which regulates the translation of target mRNAs. Thus, we assessed the effects of FMRP on the expression levels of $\mathrm{KCC} 2$ and selected components of its proteome using forebrain extracts of Fmr1 knock out mice (FX), a widely used animal model of autism. We used immunoblotting to measure the expression levels of proteins of interest in both the total and in the plasma membrane fractions from both genotypes (Figure 7a and b). KCC2 expression levels in the total lysates (TL) were unchanged between wild type (WT) and FX samples. Interestingly there was a significant decrease in KCC2 expression in the plasma membrane fraction $(\mathrm{p}=0.04)$. The $190 \mathrm{kDa}$ form of ANK3 was also reduced in the plasma membrane fraction of FX animals ( $\mathrm{p}=0.001$ ), although the $270 \mathrm{kDa}$ and $480 \mathrm{kDa}$ forms were unchanged. CNTN1 expression was reduced in FX mice compared to WT in both the TL $(\mathrm{p}=0.01)$ and PM $(\mathrm{p}=0.01)$ fractions. Finally, ITPR 1 expression in the plasma membrane fractions was also reduced in FX animals ( $\mathrm{p}=0.02)$. No significant difference in expression was observed in ANK2, NCKAP1, SHANK3, SPTAN1, or SPTBN1. Taken together, these data demonstrate that the expression of several $\mathrm{KCC} 2$-associated proteins is reduced in plasma membrane fractions from FX mouse forebrain.

\section{FMRP inactivation compromises KCC2} phosphorylation KCC2 expression levels, membrane trafficking and activity have been shown to be subject to modulation via multiple phosphorylation sites within the C-terminal cytoplasmic domain. Our proteomic studies have revealed that $\mathrm{KCC} 2$ is intimately associated with multiple targets of FMRP, many of which are scaffold/signaling molecules. Thus, we sought to analyze the effects of FMRP inactivation, and subsequent reduction of KCC2-associated protein expression, on global KCC2 phosphorylation. To do so, we immunoprecipitated KCC2 from plasma membrane fractions prepared from WT and FX mice as outlined in Figure 1. To limit dephosphorylation purified material was resolved by SDS-PAGE and visualized using Coomassie (Figure 8a). Major bands of $125 \mathrm{kDa}$ were seen with material purified on KCC2 antibody, but not control IgG. The respective bands were excised, digested with trypsin, and analyzed by LCMS/MS. LC-MS/MS confirmed the $125 \mathrm{kDa}$ bands were highly enriched in KCC2 with an average of 884 and 915 peptides detected $(n=4)$, which equates to coverage of $53 \%$ and $43 \%$, for $\mathrm{KCC} 2$ from WT and FX tissue respectively (Figure 8b).

We identified 7 high confidence KCC2 phosphorylation sites based on A-scores greater than 19, which equates to $99 \%$ confidence in assignment (Figure 8c and d). One site (S26), is located on the $\mathrm{N}$-terminus of $\mathrm{KCC} 2$, whereas the other 6 sites were located on the C-terminus (T906, T932, S940, T1007, T1009, S1022). We normalized the number of phosphorylated peptides detected for each site to the total number of peptides detected in that region and compared the ratios between $\mathrm{KCC} 2$ isolated from WT and FX. In this way we could compare changes in 
$\mathrm{KCC} 2$ and autism/epilepsy risk gene products

global KCC2 phosphorylation between WT and FX mice. This approach revealed that inactivation of FMRP resulted in the specific dephosphorylation of a subset of residues and generated insights into global phosphorylation changes in KCC2. Two of the well characterized sites, S940 and T1007, showed no changes in phosphorylation, along with two of the novel sites detected; S26, and T932. In contrast T906, T1009, and S1022, which are present in WT tissue, were completely absent in FX tissue $(n=4)$. Collectively these results demonstrate that FMRP regulates the phosphorylation of a subset of residues within the $\mathrm{C}$-terminal intracellular domain of KCC2, likely due to its control of the expression of several KCC2-interacting proteins.

\section{Discussion}

Isolation of stable multi-protein complexes
enriched in KCC2. The $\mathrm{K}+\mathrm{Cl}$ - co-transporter, $\mathrm{KCC} 2$, is expressed at the cell surface of mature neurons where it is of fundamental importance for maintaining intracellular chloride levels, and thereby the efficacy of neuronal inhibition. To gain insights into how neurons regulate the plasma membrane accumulation and activity of $\mathrm{KCC} 2$, we developed a method for the isolation of native multiprotein complexes from enriched in this transporter from brain plasma membranes. Following immuno-affinity purification, BNPAGE and LC-MS/MS we were able to isolate highly purified native preparations of $\mathrm{KCC}$, which exhibited major molecular mass species between 300-800 kDa. This methodology provided very high sequence coverage for the intracellular and extracellular domains of KCC2, maximizing the probability detecting associated proteins and post-translational modifications.

KCC2 consists of 1139 amino acids including the signal sequence, which equates to a mass of $126 \mathrm{kDa}$ without post-translational modifications. $\mathrm{KCC} 2$ is, however, subject to extensive post-translational modification including glycosylation at six sites so is often observed in a band of around $140 \mathrm{kDa}$ (39). Previous work has shown extensive aggregation of KCC2 following SDS-PAGE that results in a band at $250 \mathrm{kDa}$, but this depends on whether it is heterologously expressed or the manner in which it is prepared from neuronal tissues (40). Indeed, we see no aggregation in our samples following SDS-PAGE, possibly due to the use of low detergent concentrations and samples immediately processed for SDS-PAGE without freeze thaw cycles. Interestingly, when resolved by BN-PAGE, KCC2 protein complexes form distinct bands at $300 \mathrm{kDa}, 600 \mathrm{kDa}$ and $800 \mathrm{kDa}$. The $300 \mathrm{kDa}$ band contains approximately 6-fold more peptides for $\mathrm{KCC} 2$ than the next most abundant protein, indicating that this band consists largely of KCC2. At $300 \mathrm{kDa}$, this would indicate that in the plasma $\mathrm{KCC} 2$ exists as homodimers, which is consistent with recently published studies on recombinant KCC2 molecules visualized using Cryo-EM (39) Interestingly, the next most abundant protein in the $300 \mathrm{kDa}$ species was $\mathrm{KCC} 1$, potentially indicating that $\mathrm{KCC} 1 / \mathrm{KCC} 2$ heterodimers are present in the brain, albeit at lower levels than KCC2 homodimers. Consistent with this notion studies in oocytes suggest that KCC2 can form heterodimers with other KCCs (41). Whether these potential heterodimers are functional is unclear but are an exciting focus for future research.

The $600 \mathrm{kDa}$ and $800 \mathrm{kDa}$ bands also contained $\mathrm{KCC} 2$, together with a range of other proteins. Significantly the ratio of these associated proteins relative to $\mathrm{KCC} 2$ increased with molecular mass. Given the stringency of our methodology and the use of native conditions these species represent stable-protein complexes that primarily reside in the plasma membrane. The proteins detected by a previous proteomic analysis of KCC2 complexes (42) overlapped with $13 \%$ and $16 \%$ of the proteins we detected in the $600 \mathrm{kDa}$ and $800 \mathrm{kDa}$ bands respectively. This low degree of overlap is likely due to the methodological differences between the studies; the previous work extracted $\mathrm{KCC} 2$ complexes from a crude membrane preparation and used onbead digest prior to LC-MS/MS, rather than complexes purified from a plasma membrane fraction resolved by BN-PAGE, then distinct bands excised for analysis. The previously presented work is possibly more likely to detect transient interactions due to less sample processing. However, the method presented here ensured a sample of reduced complexity was 
$\mathrm{KCC} 2$ and autism/epilepsy risk gene products

analyzed by LC-MS/MS, resulting in a higher resolution snapshot of the proteins associated with high affinity with $\mathrm{KCC} 2$ on the neuronal plasma membrane $(43,44)$. Similarly to Mahadevan et al., we also did not detect NETO2 (45), GRIK2 (Gluk2) (46), EPB41L1 (4.1n) (47), ARHGEF7 (Beta-pix) (48), RCC1 (49) or with the signal transduction molecules; PKC, WNK, SPAK or OSR $(8,50)$. This could be either due the transient or low affinity nature of these interactions, or that these interactors are less abundant in complex with $\mathrm{KCC} 2$ than the interactors presented here, as unbiased methodologies provide information on associated proteins in rank order of abundance. LC-MS/MS further confirmed the veracity of our purification strategy as these high molecular weight species contained GABABRs, which has been previously shown to be associated with KCC2 (35). Interestingly we identified gephyrin associated with $\mathrm{KCC} 2$ in the $800 \mathrm{kDa}$ band along with CYFIP1/2, NCKAP1 and CNTN1 and other proteins that are enriched at inhibitory synapses $(51,52)$. NLGN3 was also detected, which can be present at both inhibitory and excitatory synapses (53). KCC2 has previously been shown to be in close proximity to excitatory synapses and has been established to be associated with proteins enriched at these structures $(42,54,55)$. In agreement with this we detected well characterized excitatory synapse proteins such as SHANK3, MYO5A, and DLG1 in our purifications (56-58).

KCC2 is associated with a subset of highly interconnected ASD/Epi gene products. The most striking feature of the $\mathrm{KCC} 2$ proteome is that it is highly enriched for protein products of genes associated with ASD/Epi. Perturbation of KCC2 itself is associated with autism (59) and epilepsy $(14,15,17,59)$. Of the KCC2-associated proteins, ANK2, SHANK3, and SCN2A are all ranked in the highest group of ASDs by SFARI, mutations in the latter are also a cause of Dravet syndrome (38). We selected these proteins for further investigation, along with NCKAP1 (SFARI group 2), ANK3 (SFARI Group 3), ITPR1 (SFARI Group 4 and epilepsy risk gene), CNTN1 - an in silico predicted ASD $(60,61)$, SPTAN1 (highly implicated in epilepsy) (62), and SPTBN1 (indirectly genetically implicated in
ASD) (63). These proteins were selected due to a combination of their disease implications and the number of detected peptides. They were also selected, as they are closely related to each other, including the well-established interactions between ankyrins and spectrins (64), which can recruit SCN2A at the cell surface (65). CNTN1 is also thought to interact with spectrins either directly or via CASPR1 (66). NCKAP1 is a part of the WAVE regulatory complex (WRC) that control actin dynamics (67). This complex can interact with ankyrins and SHANK3 (68).

FMRP inactivation compromises KCC2 phosphorylation. Many of the components of the KCC2 proteome are targets of FMRP. Therefore, to assess the significance of this protein network on $\mathrm{KCC} 2$, we assessed the effects of FMRP inactivation on KCC2 phosphorylation, a key regulator of transporter activity. Plasma membrane levels of the FMRP targets proteins that are also $\mathrm{KCC} 2$ binding partners; ANK3, CNTN1 and ITPR1 were decreased in FX mice as were those of $\mathrm{KCC} 2$. In WT mice KCC2 was phosphorylated on up to seven residues including T906, S940, T1007. These play a critical role in regulating $\mathrm{KCC} 2$ function $(13,69)$. In addition to this we detected phosphorylation of S1022 consistent with a recent publication (39).

We also identified 3 further sites of phosphorylation; S26, T932 and T1009 respectively (70). Significantly, inactivation of FMRP abolished T906, T1009, and S1022 phosphorylation, without impacting on that of S26, T932, S940 or T1007. It is of note that these three phosphorylation sites all lie within the intracellular $\mathrm{C}$-terminus of $\mathrm{KCC} 2$, and while T906 phosphorylation has been established to inhibit KCC2 activity, the roles that T1009 and T1022 phosphorylation play in modulating transporter function, protein-protein interactions, and/or membrane trafficking is unknown. Interestingly, T1009 and T1022 lie adjacent to, or within the isotonic domain of $\mathrm{KCC} 2$, suggesting that their phosphorylation may impact on its basal

activity. Thus, it is tempting to speculate that modified $\mathrm{KCC} 2$ phosphorylation may contribute to aberrant GABAergic signaling that 
is central to the pathophysiology of FX and other ASDs.

In conclusion we have demonstrated that $\mathrm{KCC} 2$ is a point of convergence for multiple ASD/Epi risk gene products, which may act in part to coordinate its phosphorylation. Therefore, therapies targeting $\mathrm{KCC} 2$ may have broad utility in alleviating autism and associated epilepsies with varying genetic etiologies.

Experimental Procedures. Unless otherwise stated chemicals were obtained from SigmaAldrich, St. Louis, MO, USA.

Animals Animal studies were performed according to protocols approved by the Institutional Animal Care and Use Committee of Tufts Medical Center. 8-12-week-old male and female mice were kept on a 12-hour light/dark cycle with ad libitum access to food and water.

Antibodies The following antibodies were used for immunoprecipitation (IP), immunoblot (IB), or immunocytochemistry (ICC): ANK2 (mouse, ICC, Invitrogen 33-3700), ANK2 (rabbit, IB, Bioss BS-6967R-TR), ANK3 (mouse, ICC, Neuromab 75-146), ANK3 (rabbit, IB, Synaptic Systems 386003), CNTN1 (rabbit, IB/ICC, Abcam Ab66265), ITPR1 (rabbit, IB/ICC, Alomone ACC-019), KCC2 (mouse, IP/ICC, Neuromab 75-013), KCC2 (rabbit, IB/ICC, Millipore 07-432), NCKAP1 (rabbit, IB, Abcam 126061), NCKAP1 (rabbit, ICC, Sigma HPA020449), SCN2A (mouse, ICC, Neuromab 75-024), SCN2A (rabbit, IB, Alomone ASC002), SHANK3 (rabbit, IB/ICC, Alomone APZ013), SPTAN1 (mouse, ICC, Abcam Ab11755), SPTAN1 (rabbit, IB, Cell Signaling 21225), SPTBN1 (rabbit, IB/ICC, Abcam Ab72239), $\alpha$ Tubulin (mouse, IB, Sigma T9026).

Immunoblotting Sodium dodecyl sulphate polyacrylamide gel electrophoresis (SDS-PAGE) was carried out as previously described (71). Briefly, proteins were isolated in RIPA lysis buffer $(50 \mathrm{mM}$ Tris, $150 \mathrm{mM} \mathrm{NaCl}, 0.1 \%$ SDS,
$\mathrm{KCC} 2$ and autism/epilepsy risk gene products

$0.5 \%$ sodium deoxycholate and $1 \%$ Triton X-100, $\mathrm{pH}$ 7.4) supplemented with mini cOmplete protease inhibitor and PhosSTOP phosphatase inhibitor tablets. Protein concentration was measured using a Bradford assay (Bio-Rad, Hercules, CA, USA). Samples were diluted in 2x sample buffer and $20 \mu \mathrm{g}$ of protein was loaded onto a $7 \%, 10 \%$, or $12 \%$ polyacrylamide gel depending on the molecular mass of the target protein. After separation by SDS-PAGE, proteins were transferred onto nitrocellulose membrane. Membranes were blocked in 5\% milk in trisbuffered saline $0.1 \%$ Tween-20 (TBS-T) for 1 hour, washed with TBS-T, and then probed with primary antibodies diluted in TBS-T (dilution and incubation time dependent on the antibody). The membranes were washed and incubated for 1 hour at room temperature with HRP-conjugated secondary antibodies (1:5000 - Jackson ImmunoResearch Laboratories, West Grove, PA, USA). Protein bands were visualized with Pierce ECL (ThermoFisher) and imaged using a ChemiDoc MP (Bio-Rad). Band intensity was compared to $\alpha$-tubulin as a loading control.

$B N$-PAGE For blue native poly-acrylamide gel electrophoresis (BN-PAGE), proteins were isolated using Triton lysis buffer $(150 \mathrm{mM} \mathrm{NaCl}$, $10 \mathrm{mM}$ Tris, $0.5 \%$ Triton X-100, pH 7.5). Samples were diluted in $4 \mathrm{x}$ NativePAGE sample buffer and G250 additive. Samples were loaded onto 4-16\% NativePAGE gels and run using a mini gel tank (ThermoFisher, Waltham, MA, USA). Gels were run for approximately 2 hours and then prepared for coomassie staining or immunoblotting. For coomassie staining the gels were fixed in $50 \%$ ethanol and $10 \%$ acetic acid, washed in $30 \%$ ethanol, washed in water, then stained with EZ blue stain. The gels were destained in ultrapure water, imaged using a ChemiDoc MP (Bio-Rad), and bands excised for liquid chromatography tandem mass spectrometry (LC-MS/MS). For immunoblotting, proteins were transferred to PVDF membrane overnight. The membranes were then fixed in $8 \%$ acetic acid, washed with ultrapure water and airdried before being briefly destained with $100 \%$ methanol. The membranes were then blocked, immunoblotted, and imaged as normal. 
$\mathrm{KCC} 2$ and autism/epilepsy risk gene products

Plasma membrane isolation. Plasma membrane isolation from mouse forebrain was carried out using a modified version of a previously described method (72). Briefly, mouse forebrain was rapidly isolated and placed in ice-cold starting buffer $(225 \mathrm{mM}$ mannitol, $75 \mathrm{mM}$ sucrose, $30 \mathrm{mM}$ Tris- $\mathrm{HCl}$ (pH 7.4). The tissue was then transferred to ice-cold isolation buffer $(225 \mathrm{mM}$ mannitol, $75 \mathrm{mM}$ sucrose, $0.5 \%$ (wt/vol) BSA, $0.5 \mathrm{mM}$ EGTA, 30mM Tris-HCl, pH 7.4) supplemented with mini cOmplete protease inhibitor and PhosSTOP. 5-7 brains were used per immunoprecipitation. The brains were homogenized in the isolation buffer using 14 strokes of a Dounce homogenizer. The samples were transferred to centrifuge tubes for centrifugation, which was carried out at $4^{\circ} \mathrm{C}$ throughout. The samples were initially spun at $800 x y$ for 5 minutes to remove nuclei and non lysed cells. The pellet was discarded, and the supernatant was spun again at $800 \mathrm{xg}$ for 5 minutes to remove residual nuclei and non lysed cells. The supernatant was transferred to high speed centrifuge tubes and spun at 10000xg for 10 minutes to remove mitochondria. The pellet was discarded, and the supernatant spun again at $10000 x g$ for 10 minutes to remove mitochondrial contamination. The supernatant was then spun at $25000 \mathrm{xg}$ for 20 minutes to pellet plasma membranes. The pellet was resuspended in starting buffer and spun again at 25000xg for 20 minutes to remove cytosolic and ER/Golgi contamination. Finally, the plasma membrane fraction was purified on a discontinuous sucrose gradient $(53 \%, 43 \%, 38 \%$ sucrose), and spun at $93000 x$ for 50 minutes to remove residual contamination from cytosol and other membranous compartments.

Protein purification Protein G Dynabeads (ThermoFisher) were washed 3 times with phosphate buffered saline with $0.05 \%$ Tween-20 (PBS-Tween). The beads were resuspended in PBS-Tween and incubated overnight at $4^{\circ} \mathrm{C}$ with antibodies for the target protein at an experimentally predetermined bead:antibody ratio (Figure S1). The antibody was crosslinked onto the beads by washing twice with $0.2 \mathrm{M}$ triethanolamine ( $\mathrm{pH}$ 8.2) (TEA), and then incubated for 30 minutes with $40 \mathrm{mM}$ dimethyl pimelimidate (DMP) in TEA at room temperature. The beads were transferred to $50 \mathrm{mM}$ Tris $(\mathrm{pH} 7.5)$ and incubated at room temperature for 15 minutes. The beads were then washed 3 times with PBS-Tween and resuspended in solubilized plasma membranes in ice cold Triton lysis buffer, supplemented with mini cOmplete protease inhibitor and PhosSTOP. The immunoprecipitation reaction was incubated overnight at $4^{\circ} \mathrm{C}$. The beads were then washed 3 times with PBS-Tween and eluted either with $2 \mathrm{x}$ sample buffer (for SDS-PAGE) or soft elution buffer $(0.2 \%$ (w/V) SDS, $0.1 \%(\mathrm{~V} / \mathrm{V})$ Tween-20, $50 \mathrm{mM}$ Tris-HCl, $\mathrm{pH}=8.0$ ) (30) (for BN-PAGE).

Protein and phosphosite identification Excised gel bands were cut into $1 \mathrm{~mm}_{3}$ pieces and subjected to modified in-gel trypsin digestion, as previously described (73). Briefly, gel pieces were washed and dehydrated with acetonitrile for 10 minutes and then completely dried in a speedvac. Gel pieces were rehydrated with $50 \mathrm{mM}$ ammonium bicarbonate solution containing 12.5 $\mathrm{ng} / \mu \mathrm{l}$ modified sequencing-grade trypsin (Promega, Madison, WI, USA) and incubated for 45 minutes at $4^{\circ} \mathrm{C}$. The excess trypsin solution was removed and replaced with $50 \mathrm{mM}$ ammonium bicarbonate solution. Samples were then incubated at $37^{\circ} \mathrm{C}$ overnight. Peptides were extracted by washing with $50 \%$ acetonitrile and $1 \%$ formic acid. The extracts were then dried in a speed-vac ( 1 hour). The samples were stored at $4^{\circ} \mathrm{C}$ until analysis. Before analysis the samples were reconstituted in $5-10 \mu \mathrm{l}$ of HPLC solvent A ( $2.5 \%$ acetonitrile, $0.1 \%$ formic acid). A nanoscale reverse-phase HPLC capillary column was created by packing $2.6 \mu \mathrm{m} \mathrm{C} 18$ spherical silica beads into a fused silica capillary $(100 \mu \mathrm{m}$ inner diameter $\mathrm{x} \sim 30 \mathrm{~cm}$ length) with a flame-drawn tip (74). After equilibrating the column each sample was loaded via a Famos auto sampler (LC Packings, San Francisco, CA, USA) onto the column. A gradient was formed and peptides were eluted with increasing concentrations of solvent B ( $97.5 \%$ acetonitrile, $0.1 \%$ formic acid). As each peptide was eluted, they were subjected to electrospray ionization and then entered into an LTQ Orbitrap Velos Pro ion-trap mass spectrometer (Thermo Fisher Scientific, San Jose, CA, USA). Eluting peptides were detected, 
KCC2 and autism/epilepsy risk gene products

isolated, and fragmented to produce a tandem mass spectrum of specific fragment ions for each peptide. Peptide sequences (and hence protein identity) were determined by matching protein or translated nucleotide databases with the acquired fragmentation pattern using Sequest (ThermoFinnigan, San Jose, CA, USA) (75). For phosphopetide detection the modification of 79.9663 mass units to serine, threonine, and tyrosine was included in the database searches. Phosphorylation assignments were determined by the A score algorithm (76). All databases include a reversed version of all the sequences and the data was filtered to between a one and two percent peptide false discovery rate.

Primary neuron culture Mouse cortical and hippocampal mixed cultures were created from P0 mouse pups as previously described (77). Briefly, P0 mice were anesthetized on ice and the brains removed. The brains were dissected in Hank's buffered salt solution (Invitrogen/ThermoFisher) with $10 \mathrm{mM}$ HEPES. The cortices and hippocampi were trypsinized and triturated to dissociate the neurons. Cells were counted using a hemocytometer and plated on poly-l-lysine-coated $13 \mathrm{~mm}$ coverslips in $24-$ well plate wells at a density of $2 \times 105$ cells $/ \mathrm{ml}$ in Neurobasal media (Invitrogen/ThermoFisher). At days in vitro (DIV) 18, cells were fixed in $4 \%$ paraformaldehyde in PBS for 10 minutes at room temperature. They were then placed in PBS at $4^{\circ} \mathrm{C}$ until being processed for immunocytochemistry.

Immunocytochemistry Fixed primary neurons were permeabilized for 1 hour in blocking solution (3\% BSA, 10\% normal goat serum, 0.2 M glycine in PBS with $0.1 \%$ Triton-X100). Cells were exposed to primary and then fluorophoreconjugated secondary antibodies diluted in blocking solution for $1 \mathrm{~h}$ each at room temperature. The coverslips were then washed in PBS, dried, and mounted onto microscope slides with Fluoromount-G (SouthernBiotech, Birmingham, AL, USA). The samples were imaged using a Nikon Eclipse Ti (Nikon Instruments, Melville, NY, USA) or Leica Falcon (Leica Microsystems, Buffalo Grove, IL, USA) confocal microscope using a 60x oil immersion objective lens. Image settings were manually assigned for each fluorescent channel. For image processing, the background was subtracted for each fluorescent channel and the median filter was applied (Radius $=1$ pixel) on Fiji Software (78). The line scans (white lines) used for protein localization were generated using the PlotProfile function in FIJI and represent the fluorescent intensity of single pixels against the distance of a manually drawn line (approximately $1 \mu \mathrm{m}$ ) on dendrites.

Densitometry For Western blot analysis, bands from raw images were analyzed using the FIJI densitometry features. Biological replicates were run on the same gels for comparison, and area under the curve was calculated for each band. Average signal and standard error were calculated for each treatment group and ANOVA carried out using $\mathrm{R}$ for statistical comparison of protein expression levels.

Bioinformatics and Statistics Detected peptides for each Uniprot ID were compared to the Uniprot mouse reference sequence for annotation using R. KCC2 peptide sequences were aligned to the mouse KCC2 reference sequence (Uniprot ID: Q91V14) using the Multiple Sequence Alignment (MSA) package in $\mathrm{R}$ (accessed January 10th, 2019). Proteins with significant affinity for IgG alone were removed according to $(31,32)$ along with proteins with fewer than 3 total peptides across 3 of 4 replicates. Total peptide counts for detected proteins in each protein band were compared across 4 biological repeats, Venn diagrams produced using the Vennerable package in R (accessed January 10th, 2019), and only proteins detected in all repeats considered for downstream analysis. These total peptide counts for the lists of proteins contained within each gel band were normalized by ztransformation and used for Principle Component Analysis (PCA), which was carried out using the PCA functions in R. The protein lists for each band were ordered according to total peptide counts, a measure for relative abundance, and the top 150 proteins used for network analysis. The protein lists were compared against the latest version of the StringDB database (34) to establish known interactions and the Gene Ontology (GO) terms for each protein (Table S3 and S4). The interaction for each protein with $\mathrm{KCC} 2$ was 
bioRxiv preprint doi: https://doi.org/10.1101/2020.03.02.973859; this version posted March 2, 2020. The copyright holder for this preprint (which was not certified by peer review) is the author/funder. All rights reserved. No reuse allowed without permission.

KCC2 and autism/epilepsy risk gene products

imputed using only high confidence, experimental evidence and network diagrams were constructed in $\mathrm{R}$ using the igraph package (accessed February 1st, 2019). A master list of epilepsy and autism risk genes was constructed from the SFARI database (29), the list of genes that are the target of FMRP (36), and the

EpilepsyGene (37) database (Table S5). This data was overlaid onto the $\mathrm{KCC} 2$ proteome to assess the abundance of autism/epilepsy risk genes associated with $\mathrm{KCC} 2$. 
products

KCC2 and autism/epilepsy risk gene

Acknowledgements: S.J.M. is supported by National Institutes of Health (NIH)-National Institute of Neurological Disorders and Stroke Grants NS051195, NS056359, NS081735, R21NS080064 and NS087662; NIH-National Institute of Mental Health Grant MH097446,

Conflict of interest statement. S.J.M serves as a consultant for AstraZeneca, and SAGE Therapeutics, relationships that are regulated by Tufts University. S.J.M holds stock in SAGE Therapeutics.

Author Contributions. JLS and SJM conceptualized the project, analyzed the data and wrote the paper. GK performed immunocytochemistry experiments. CC and QR performed western blot experiments. MARS and CEB maintained the mouse colony and performed genotyping. TZD and NJB edited the paper.

\section{References}

1. Moore, Y. E., Kelley, M. R., Brandon, N. J., Deeb, T. Z., and Moss, S. J. (2017) Seizing Control of KCC2: A New Therapeutic Target for Epilepsy. Trends Neurosci. 40, 555-571

2. Ben-Ari, Y., Khalilov, I., Kahle, K. T., and Cherubini, E. (2012) The GABA excitatory/inhibitory shift in brain maturation and neurological disorders. Neuroscientist. $10.1177 / 1073858412438697$

3. Li, H., Tornberg, J., Kaila, K., Airaksinen, M. S., and Rivera, C. (2002) Patterns of cationchloride cotransporter expression during embryonic rodent CNS development. Eur. J. Neurosci. 10.1046/j.1460-9568.2002.02419.x

4. Uvarov, P., Ludwig, A., Markkanen, M., Rivera, C., and Airaksinen, M. S. (2006) Upregulation of the neuron-specific $\mathrm{K}+/ \mathrm{Cl}$ - cotransporter expression by transcription factor early growth response 4. J. Neurosci. 10.1523/JNEUROSCI.4731-06.2006

5. Payne, J. A. (1997) Functional characterization of the neuronal-specific K-Cl cotransporter: Implications for $[\mathrm{K}+](\mathrm{o})$ regulation. Am. J. Physiol. - Cell Physiol. 10.1152/ajpcell.1997.273.5.c1516

6. Rivera, C., Voipio, J., Payne, J. A., Ruusuvuori, E., Lahtinen, H., Lamsa, K., Pirvola, U., Saarma, M., and Kaila, K. (1999) The K+/Cl- co-transporter KCC2 renders GABA hyperpolarizing during neuronal maturation. Nature. 10.1038/16697

7. Sedmak, G., Jovanov-Milošević, N., Ulamec, M. P. M., Krušlin, B., Kaila, K., and Judaš, M. (2016) Developmental expression patterns of KCC2 and functionally associated molecules in the human brain. Cereb. Cortex. 10.1093/cercor/bhv218

8. Lee, H. H. C., Walker, J. A., Williams, J. R., Goodier, R. J., Payne, J. A., and Moss, S. J. (2007) Direct protein kinase C-dependent phosphorylation regulates the cell surface stability and activity of the potassium chloride cotransporter KCC2. J. Biol. Chem. 10.1074/jbc.M705053200

9. Rinehart, J., Maksimova, Y. D., Tanis, J. E., Stone, K. L., Hodson, C. A., Zhang, J., Risinger, M., Pan, W., Wu, D., Colangelo, C. M., Forbush, B., Joiner, C. H., Gulcicek, E. 
products

$$
\text { KCC2 and autism/epilepsy risk gene }
$$

E., Gallagher, P. G., and Lifton, R. P. (2009) Sites of Regulated Phosphorylation that Control K-Cl Cotransporter Activity. Cell. 10.1016/j.cell.2009.05.031

10. Lee, H. H. C., Deeb, T. Z., Walker, J. A., Davies, P. A., and Moss, S. J. (2011) NMDA receptor activity downregulates $\mathrm{KCC} 2$ resulting in depolarizing GABAA receptormediated currents. Nat. Neurosci. 14, 736-743

11. Titz, S., Sammler, E. M., and Hormuzdi, S. G. (2015) Could tuning of the inhibitory tone involve graded changes in neuronal chloride transport? Neuropharmacology. 10.1016/j.neuropharm.2015.03.026

12. Moore, Y. E., Conway, L. C., Wobst, H. J., Brandon, N. J., Deeb, T. Z., and Moss, S. J. (2019) Developmental Regulation of KCC2 Phosphorylation Has Long-Term Impacts on Cognitive Function. Front. Mol. Neurosci. 10.3389/fnmol.2019.00173

13. Pisella, L. I., Gaiarsa, J. L., Diabira, D., Zhang, J., Khalilov, I., Duan, J. J., Kahle, K. T., and Medina, I. (2019) Impaired regulation of KCC2 phosphorylation leads to neuronal network dysfunction and neurodevelopmental pathology. Sci. Signal. 10.1126/scisignal.aay0300

14. Stödberg, T., McTague, A., Ruiz, A. J., Hirata, H., Zhen, J., Long, P., Farabella, I., Meyer, E., Kawahara, A., Vassallo, G., Stivaros, S. M., Bjursell, M. K., Stranneheim, H., Tigerschiöld, S., Persson, B., Schorge, S., Reith, M. E., Topf, M., Kullmann, D. M., Harvey, R. J., Wedell, A., and Kurian, M. A. (2015) ARTICLE Mutations in SLC12A5 in epilepsy of infancy with migrating focal seizures. Nat. Commun. 17, 33

15. Saitsu, H., Watanabe, M., Akita, T., Ohba, C., Sugai, K., Ong, W. P., Shiraishi, H., Yuasa, S., Matsumoto, H., Beng, K. T., Saitoh, S., Miyatake, S., Nakashima, M., Miyake, N., Kato, M., Fukuda, A., and Matsumoto, N. (2016) Impaired neuronal KCC2 function by biallelic SLC12A5 mutations in migrating focal seizures and severe developmental delay. Sci. Rep. 10.1038/srep30072

16. Saito, T., Ishii, A., Sugai, K., Sasaki, M., and Hirose, S. (2017) A de novo missense mutation in SLC12A5 found in a compound heterozygote patient with epilepsy of infancy with migrating focal seizures. Clin. Genet. 10.1111/cge.13049

17. Kelley, M. R., Cardarelli, R. A., Smalley, J. L., Ollerhead, T. A., Andrew, P. M., Brandon, N. J., Deeb, T. Z., and Moss, S. J. (2018) Locally Reducing KCC2 Activity in the Hippocampus is Sufficient to Induce Temporal Lobe Epilepsy. EBioMedicine. 32, 62-71

18. Chen, L., Wan, L., Wu, Z., Ren, W., Huang, Y., Qian, B., and Wang, Y. (2017) KCC2 downregulation facilitates epileptic seizures. Sci. Rep. 10.1038/s41598-017-00196-7

19. Jaenisch, N., Witte, O. W., and Frahm, C. (2010) Downregulation of potassium chloride cotransporter KCC2 after transient focal cerebral ischemia. Stroke. 10.1161/STROKEAHA.109.570424

20. Mapplebeck, J. C. S., Lorenzo, L. E., Lee, K. Y., Gauthier, C., Muley, M. M., De Koninck, Y., Prescott, S. A., and Salter, M. W. (2019) Chloride Dysregulation through Downregulation of KCC2 Mediates Neuropathic Pain in Both Sexes. Cell Rep. 10.1016/j.celrep.2019.06.059 
products

KCC2 and autism/epilepsy risk gene

21. Tyzio, R., Nardou, R., Ferrari, D. C., Tsintsadze, T., Shahrokhi, A., Eftekhari, S., Khalilov, I., Tsintsadze, V., Brouchoud, C., Chazal, G., Lemonnier, E., Lozovaya, N., Burnashev, N., and Ben-Ari, Y. (2014) Oxytocin-mediated GABA inhibition during delivery attenuates autism pathogenesis in rodent offspring. Science (80-. ). $10.1126 /$ science. 1247190

22. Deidda, G., Parrini, M., Naskar, S., Bozarth, I. F., Contestabile, A., and Cancedda, L. (2015) Reversing excitatory GABA A R signaling restores synaptic plasticity and memory in a mouse model of Down syndrome. Nat. Med. 10.1038/nm.3827

23. He, Q., Nomura, T., Xu, J., and Contractor, A. (2014) The Developmental Switch in GABA Polarity Is Delayed in Fragile X Mice. J. Neurosci. 34, 446-450

24. Duarte, S. T., Armstrong, J., Roche, A., Ortez, C., Pérez, A., O'Callaghan, M. del M., Pereira, A., Sanmartí, F., Ormazábal, A., Artuch, R., Pineda, M., and García-Cazorla, A. (2013) Abnormal Expression of Cerebrospinal Fluid Cation Chloride Cotransporters in Patients with Rett Syndrome. PLoS One. 10.1371/journal.pone.0068851

25. Tang, X., Kim, J., Zhou, L., Wengert, E., Zhang, L., Wu, Z., Carromeu, C., Muotri, A. R., Marchetto, M. C. N., Gage, F. H., and Chen, G. (2016) KCC2 rescues functional deficits in human neurons derived from patients with Rett syndrome. Proc. Natl. Acad. Sci. U. S. A. $10.1073 /$ pnas. 1524013113

26. Tang, X., Drotar, J., Li, K., Clairmont, C. D., Brumm, A. S., Sullins, A. J., Wu, H., Liu, X. S., Wang, J., Gray, N. S., Sur, M., and Jaenisch, R. (2019) Pharmacological enhancement of KCC2 gene expression exerts therapeutic effects on human Rett syndrome neurons and Mecp2 mutant mice. Sci. Transl. Med. 10.1126/scitranslmed.aau0164

27. Kazdoba, T. M., Leach, P. T., Yang, M., Silverman, J. L., Solomon, M., and Crawley, J. N. (2016) Translational mouse models of autism: Advancing toward pharmacological therapeutics. in Current Topics in Behavioral Neurosciences, 10.1007/7854_2015_5003

28. Duda, M., Zhang, H., Li, H. D., Wall, D. P., Burmeister, M., and Guan, Y. (2018) Brainspecific functional relationship networks inform autism spectrum disorder gene prediction. Transl. Psychiatry. 10.1038/s41398-018-0098-6

29. Abrahams, B. S., Arking, D. E., Campbell, D. B., Mefford, H. C., Morrow, E. M., Weiss, L. A., Menashe, I., Wadkins, T., Banerjee-Basu, S., and Packer, A. (2013) SFARI Gene 2.0: A community-driven knowledgebase for the autism spectrum disorders (ASDs). Mol. Autism. 10.1186/2040-2392-4-36

30. Antrobus, R., and Borner, G. H. H. (2011) Improved elution conditions for native coimmunoprecipitation. PLoS One. 6, e18218

31. Mellacheruvu, D., Wright, Z., Couzens, A. L., Lambert, J. P., St-Denis, N. A., Li, T., Miteva, Y. V., Hauri, S., Sardiu, M. E., Low, T. Y., Halim, V. A., Bagshaw, R. D., Hubner, N. C., Al-Hakim, A., Bouchard, A., Faubert, D., Fermin, D., Dunham, W. H., Goudreault, M., Lin, Z. Y., Badillo, B. G., Pawson, T., Durocher, D., Coulombe, B., Aebersold, R., Superti-Furga, G., Colinge, J., Heck, A. J. R., Choi, H., Gstaiger, M., Mohammed, S., Cristea, I. M., Bennett, K. L., Washburn, M. P., Raught, B., Ewing, R. M., Gingras, A. C., and Nesvizhskii, A. I. (2013) The CRAPome: A contaminant repository for affinity purification-mass spectrometry data. Nat. Methods. 
products

KCC2 and autism/epilepsy risk gene

\section{$10.1038 /$ nmeth. 2557}

32. Nakamura, Y., Morrow, D. H., Modgil, A., Huyghe, D., Deeb, T. Z., Lumb, M. J., Davies, P. A., and Moss, S. J. (2016) Proteomic characterization of inhibitory synapses using a novel phluorin-tagged $\gamma$-aminobutyric acid receptor, type a (gabaa), $\alpha 2$ subunit knock-in mouse. J. Biol. Chem. 291, 12394-12407

33. Hilario, M., and Kalousis, A. (2008) Approaches to dimensionality reduction in proteomic biomarker studies. Brief. Bioinform. 10.1093/bib/bbn005

34. Szklarczyk, D., Gable, A. L., Lyon, D., Junge, A., Wyder, S., Huerta-Cepas, J., Simonovic, M., Doncheva, N. T., Morris, J. H., Bork, P., Jensen, L. J., and Von Mering, C. (2019) STRING v11: Protein-protein association networks with increased coverage, supporting functional discovery in genome-wide experimental datasets. Nucleic Acids Res. 10.1093/nar/gky1131

35. Wright, R., Newey, S. E., Ilie, A., Wefelmeyer, W., Raimondo, J. V., Ginham, R., Jeffrey Mcllhinney, R. A., and Akerman, C. J. (2017) Neuronal chloride regulation via KCC2 is modulated through a GABAB receptor protein complex. J. Neurosci. 10.1523/JNEUROSCI.2164-16.2017

36. Korb, E., Herre, M., Zucker-Scharff, I., Gresack, J., Allis, C. D., and Darnell, R. B. (2017) Excess Translation of Epigenetic Regulators Contributes to Fragile X Syndrome and Is Alleviated by Brd4 Inhibition. Cell. 10.1016/j.cell.2017.07.033

37. Ran, X., Li, J., Shao, Q., Chen, H., Lin, Z., Sun, Z. S., and Wu, J. (2015) EpilepsyGene: A genetic resource for genes and mutations related to epilepsy. Nucleic Acids Res. 10.1093/nar/gku943

38. Shi, X., Yasumoto, S., Nakagawa, E., Fukasawa, T., Uchiya, S., and Hirose, S. (2009) Missense mutation of the sodium channel gene SCN2A causes Dravet syndrome. Brain Dev. 10.1016/j.braindev.2009.08.009

39. Agez, M., Schultz, P., Medina, I., Baker, D. J., Burnham, M. P., Cardarelli, R. A., Conway, L. C., Garnier, K., Geschwindner, S., Gunnarsson, A., McCall, E. J., Frechard, A., Audebert, S., Deeb, T. Z., Moss, S. J., Brandon, N. J., Wang, Q., Dekker, N., and Jawhari, A. (2017) Molecular architecture of potassium chloride co-transporter KCC2. Sci. Rep. 10.1038/s41598-017-15739-1

40. Medina, I., Friedel, P., Rivera, C., Kahle, K. T., Kourdougli, N., Uvarov, P., and Pellegrino, C. (2014) Current view on the functional regulation of the neuronal K+-Clcotransporter KCC2. Front. Cell. Neurosci. 10.3389/fncel.2014.00027

41. Simard, C. F., Bergeron, M. J., Frenette-Cotton, R., Carpentier, G. A., Pelchat, M. E., Caron, L., and Isenring, P. (2007) Homooligomeric and heterooligomeric associations between $\mathrm{K}+-\mathrm{Cl}$ - cotransporter isoforms and between $\mathrm{K}+-\mathrm{Cl}$ - and $\mathrm{Na}+-\mathrm{K}+-\mathrm{Cl}$ cotransporters. J. Biol. Chem. 10.1074/jbc.M607811200

42. Mahadevan, V., Khademullah, C. S., Dargaei, Z., Chevrier, J., Uvarov, P., Kwan, J., Bagshaw, R. D., Pawson, T., Emili, A., De Koninck, Y., Anggono, V., Airaksinen, M., and Woodin, M. A. (2017) Native KCC2 interactome reveals PACSIN1 as a critical regulator of synaptic inhibition. Elife. 10.7554/eLife.28270.001 
products

KCC2 and autism/epilepsy risk gene

43. Picotti, P., Bodenmiller, B., Mueller, L. N., Domon, B., and Aebersold, R. (2009) Full Dynamic Range Proteome Analysis of S. cerevisiae by Targeted Proteomics. Cell. 10.1016/j.cell.2009.05.051

44. Angel, T. E., Aryal, U. K., Hengel, S. M., Baker, E. S., Kelly, R. T., Robinson, E. W., and Smith, R. D. (2012) Mass spectrometry-based proteomics: Existing capabilities and future directions. Chem. Soc. Rev. 10.1039/c2cs15331a

45. Ivakine, E. A., Acton, B. A., Mahadevan, V., Ormond, J., Tang, M., Pressey, J. C., Huang, M. Y., Ng, D., Delpire, E., Salter, M. W., Woodin, M. A., and McInnes, R. R. (2013) Neto2 is a KCC2 interacting protein required for neuronal Cl- regulation in hippocampal neurons. Proc. Natl. Acad. Sci. U. S. A. 10.1073/pnas.1212907110

46. Mahadevan, V., Pressey, J. C., Acton, B. A., Uvarov, P., Huang, M. Y., Chevrier, J., Puchalski, A., Li, C. M., Ivakine, E. A., Airaksinen, M. S., Delpire, E., McInnes, R. R., and Woodin, M. A. (2014) Kainate Receptors Coexist in a Functional Complex with KCC2 and Regulate Chloride Homeostasis in Hippocampal Neurons. Cell Rep. 10.1016/j.celrep.2014.05.022

47. Li, H., Khirug, S., Cai, C., Ludwig, A., Blaesse, P., Kolikova, J., Afzalov, R., Coleman, S. K., Lauri, S., Airaksinen, M. S., Keinänen, K., Khiroug, L., Saarma, M., Kaila, K., and Rivera, C. (2007) KCC2 Interacts with the Dendritic Cytoskeleton to Promote Spine Development. Neuron. 10.1016/j.neuron.2007.10.039

48. Chevy, Q., Heubl, M., Goutierre, M., Backer, S., Moutkine, I., Eugène, E., Bloch-Gallego, E., Lévi, S., and Poncer, J. C. (2015) KCC2 gates activity-driven AMPA receptor traffic through Cofilin phosphorylation. J. Neurosci. 10.1523/JNEUROSCI.1735-15.2015

49. Garbarini, N., and Delpire, E. (2008) The RCC1 domain of Protein Associated with Myc (PAM) interacts with and regulates KCC2. Cell. Physiol. Biochem. 10.1159/000149781

50. Friedel, P., Kahle, K. T., Zhang, J., Hertz, N., Pisella, L. I., Buhler, E., Schaller, F., Duan, J., Khanna, A. R., Bishop, P. N., Shokat, K. M., and Medina, I. (2015) WNK1-regulated inhibitory phosphorylation of the KCC2 cotransporter maintains the depolarizing action of GABA in immature neurons. Sci. Signal. 10.1126/scisignal.aaa0354

51. Lu, W., Bromley-Coolidge, S., and Li, J. (2017) Regulation of GABAergic synapse development by postsynaptic membrane proteins. Brain Res. Bull. 10.1016/j.brainresbull.2016.07.004

52. Davenport, E. C., Szulc, B. R., Drew, J., Taylor, J., Morgan, T., Higgs, N. F., LópezDoménech, G., and Kittler, J. T. (2019) Autism and Schizophrenia-Associated CYFIP1 Regulates the Balance of Synaptic Excitation and Inhibition. Cell Rep. 26, 2037-2051.e6

53. Nguyen, Q. A., Horn, M. E., and Nicoll, R. A. (2016) Distinct roles for extracellular and intracellular domains in neuroligin function at inhibitory synapses. Elife.

10.7554/eLife. 19236

54. Gulyás, A. I., Sík, A., Payne, J. A., Kaila, K., and Freund, T. F. (2001) The KCl cotransporter, $\mathrm{KCC} 2$, is highly expressed in the vicinity of excitatory synapses in the rat hippocampus. Eur. J. Neurosci. 10.1046/j.0953-816X.2001.01600.x 
products

KCC2 and autism/epilepsy risk gene

55. Chamma, I., Chevy, Q., Poncer, J. C., and Lévi, S. (2012) Role of the neuronal K-Cl cotransporter KCC2 in inhibitory and excitatory neurotransmission. Front. Cell. Neurosci. 6, 5

56. Howard, M. A., Elias, G. M., Elias, L. A. B., Swat, W., and Nicoll, R. A. (2010) The role of SAP97 in synaptic glutamate receptor dynamics. Proc. Natl. Acad. Sci. U. S. A. 10.1073/pnas.0914422107

57. Sheng, M., and Kim, E. (2000) The Shank family of scaffold proteins. J. Cell Sci.

58. Kneussel, M., and Wagner, W. (2013) Myosin motors at neuronal synapses: Drivers of membrane transport and actin dynamics. Nat. Rev. Neurosci. 10.1038/nrn3445

59. Merner, N. D., Chandler, M. R., Bourassa, C., Liang, B., Khanna, A. R., Dion, P., Rouleau, G. A., and Kahle, K. T. (2015) Regulatory domain or CPG site variation in SLC12A5, encoding the chloride transporter KCC2, in human autism and schizophrenia. Front. Cell. Neurosci. 10.3389/fncel.2015.00386

60. Murdoch, J. D., Gupta, A. R., Sanders, S. J., Walker, M. F., Keaney, J., Fernandez, T. V., Murtha, M. T., Anyanwu, S., Ober, G. T., Raubeson, M. J., DiLullo, N. M., Villa, N., Waqar, Z., Sullivan, C., Gonzalez, L., Willsey, A. J., Choe, S. Y., Neale, B. M., Daly, M. J., and State, M. W. (2015) No Evidence for Association of Autism with Rare Heterozygous Point Mutations in Contactin-Associated Protein-Like 2 (CNTNAP2), or in Other Contactin-Associated Proteins or Contactins. PLoS Genet. 10.1371/journal.pgen.1004852

61. Mosca, E., Bersanelli, M., Gnocchi, M., Moscatelli, M., Castellani, G., Milanesi, L., and Mezzelani, A. (2017) Network diffusion-based prioritization of autism risk genes identifies significantly connected gene modules. Front. Genet. 10.3389/fgene.2017.00129

62. Tohyama, J., Nakashima, M., Nabatame, S., Gaik-Siew, C., Miyata, R., Rener-Primec, Z., Kato, M., Matsumoto, N., and Saitsu, H. (2015) SPTAN1 encephalopathy: Distinct phenotypes and genotypes. J. Hum. Genet. 10.1038/jhg.2015.5

63. Kim, H. G., Kishikawa, S., Higgins, A. W., Seong, I. S., Donovan, D. J., Shen, Y., Lally, E., Weiss, L. A., Najm, J., Kutsche, K., Descartes, M., Holt, L., Braddock, S., Troxell, R., Kaplan, L., Volkmar, F., Klin, A., Tsatsanis, K., Harris, D. J., Noens, I., Pauls, D. L., Daly, M. J., MacDonald, M. E. E., Morton, C. C., Quade, B. J., and Gusella, J. F. (2008) Disruption of Neurexin 1 Associated with Autism Spectrum Disorder. Am. J. Hum. Genet. 10.1016/j.ajhg.2007.09.011

64. Susuki, K., and Rasband, M. N. (2008) Spectrin and ankyrin-based cytoskeletons at polarized domains in myelinated axons. Exp. Biol. Med. 10.3181/0709-MR-243

65. Bouzidi, M., Tricaud, N., Giraud, P., Kordeli, E., Caillol, G., Deleuze, C., Couraud, F., and Alcaraz, G. (2002) Interaction of the Nav1.2a subunit of the voltage-dependent sodium channel with nodal ankyrinG. In vitro mapping of the interacting domains and association in synaptosomes. J. Biol. Chem. 10.1074/jbc.M201760200

66. Querol, L., Devaux, J., Rojas-Garcia, R., and Illa, I. (2017) Autoantibodies in chronic inflammatory neuropathies: Diagnostic and therapeutic implications. Nat. Rev. Neurol. 10.1038/nrneurol.2017.84 
products

KCC2 and autism/epilepsy risk gene

67. Eden, S., Rohatgi, R., Podtelejnikov, A. V., Mann, M., and Kirschner, M. W. (2002) Mechanism of regulation of WAVE1-induced actin nucleation by Rac1 and Nck. Nature. 10.1038 /nature00859

68. Chen, B., Brinkmann, K., Chen, Z., Pak, C. W., Liao, Y., Shi, S., Henry, L., Grishin, N. V., Bogdan, S., and Rosen, M. K. (2014) The WAVE regulatory complex links diverse receptors to the actin cytoskeleton. Cell. 10.1016/j.cell.2013.11.048

69. Moore, Y. E., Deeb, T. Z., Chadchankar, H., Brandon, N. J., and Moss, S. J. (2018) Potentiating KCC2 activity is sufficient to limit the onset and severity of seizures. Proc. Natl. Acad. Sci. U. S. A. 10.1073/pnas.1810134115

70. Weber, M., Hartmann, A. M., Beyer, T., Ripperger, A., and Nothwang, H. G. (2014) A novel regulatory locus of phosphorylation in the $\mathrm{C}$ terminus of the potassium chloride cotransporter KCC2 that interferes with n-ethylmaleimide or staurosporine-mediated activation. J. Biol. Chem. 10.1074/jbc.M114.567834

71. Schiavon, E., Smalley, J. L., Newton, S., Greig, N. H., and Forsythe, I. D. (2018) Neuroinflammation and ER-stress are key mechanisms of acute bilirubin toxicity and hearing loss in a mouse model. PLoS One. 13, e0201022

72. Suski, J. M., Lebiedzinska, M., Wojtala, A., Duszynski, J., Giorgi, C., Pinton, P., and Wieckowski, M. R. (2014) Isolation of plasma membrane-associated membranes from rat liver. Nat. Protoc. 9, 312-322

73. Shevchenko, A., Wilm, M., Vorm, O., and Mann, M. (1996) Mass spectrometric sequencing of proteins from silver-stained polyacrylamide gels. Anal. Chem. $10.1021 / \mathrm{ac} 950914 \mathrm{~h}$

74. Peng, J., and Gygi, S. P. (2001) Proteomics: The move to mixtures. J. Mass Spectrom. 10.1002/jms.229

75. Eng, Jimmy K., Ashley L. McCormack, and J. R. Y. (1994) An Approach to correlate Tandem Mass Spectral Data of Peptides with Amino Acid Sequences in a Protien Database. J. Am. Soc. Mass Spectrom.

76. Beausoleil, S. A., Villén, J., Gerber, S. A., Rush, J., and Gygi, S. P. (2006) A probabilitybased approach for high-throughput protein phosphorylation analysis and site localization. Nat. Biotechnol. 10.1038/nbt1240

77. Kelley, M. R., Cardarelli, R. A., Smalley, J. L., Ollerhead, T. A., Andrew, P. M., Brandon, N. J., Deeb, T. Z., and Moss, S. J. (2018) Locally Reducing KCC2 Activity in the Hippocampus is Sufficient to Induce Temporal Lobe Epilepsy. EBioMedicine. 10.1016/j.ebiom.2018.05.029

78. Schindelin, J., Arganda-Carreras, I., Frise, E., Kaynig, V., Longair, M., Pietzsch, T., Preibisch, S., Rueden, C., Saalfeld, S., Schmid, B., Tinevez, J. Y., White, D. J., Hartenstein, V., Eliceiri, K., Tomancak, P., and Cardona, A. (2012) Fiji: An open-source platform for biological-image analysis. Nat. Methods. 10.1038/nmeth.2019

\section{FIGURE LEGENDS}


products

KCC2 and autism/epilepsy risk gene

Figure 1. Highly enriched KCC2-containing protein complexes were isolated from purified plasma membranes from mouse forebrain. A. Differential centrifugation of homogenized forebrain from 8-12-week-old mice was used to fractionate cellular organelle and obtain an enriched plasma membrane fraction. B. Western blots of the organelle fractions were used to measure the abundance of organelle markers; HSP90 (cytosol), HSP60 (mitochondria), calreticulin (ER/Golgi), n-Cadherin (n-Cadh) (plasma membrane). KCC2 abundance was also measured to confirm KCC2 enrichment in the plasma membrane fraction. C. Blue Native PAGE (BN-PAGE) was carried out on plasma membrane lysates, and immunoprecipitated KCC2 to resolve the native protein complexes that contain $\mathrm{KCC} 2$. These were correlated with protein bands observed by Coomassie staining. D. Detected peptides were mapped to the KCC2 reference sequence to determine $\mathrm{KCC} 2$ sequence coverage obtained from LC-MS/MS of BN-PAGE protein bands produced following KCC2 IP. Bar charts of the KCC2 sequence coverage expressed as a percentage of the full sequence and by total KCC2 peptides detected $(n=4)$.

Figure 2. Stable protein complexes contain large amounts of KCC2 and a robust set of associated proteins, which differ subtly between the different molecular weight bands. A. Pie charts showing the average number of total KCC2 peptides detected by LC-MS/MS relative to the average number of total peptides detected for all other proteins in each molecular weight complex. B. Venn diagrams showing the number and overlap of KCC2-associated proteins identified in each of 4 biological replicates in each molecular weight complex. C. Venn diagram showing the overlap in associated proteins detected in at least 3 of the 4 replicates for each molecular weight complex. D. PCA analysis of each biological replicate for each molecular weight complex based on their protein composition.

Figure 3. KCC2 is associated with a robust set of proteins from multiple functional classes, with some highly interconnected subnetworks. A. A network diagram including the 150 most abundant proteins from the $600 \mathrm{kDa}$ complex based on total peptide counts. Known interactions were obtained using stringent high confidence, direct experimental association parameters from StringDB. These were used to construct a network diagram of protein nodes and arrows to indicate known interactions. The interactions for each protein with $\mathrm{KCC} 2$ were included as discovered here. An overlay of gene ontology (GO) terms was used to provide protein classification information. $\mathbf{B}$. A network diagram for the most abundant 150 proteins in the $800 \mathrm{kDa}$ complex, analyzed as described above $(n=4)$.

Figure 4. The KCC2 proteome is highly enriched for autism spectrum disorder and epilepsy risk gene products. A. A network diagram of $\mathrm{KCC} 2$-associated proteins from the $600 \mathrm{kDa}$ complex, that are also the protein products of genes associated with ASD or epilepsy. The known protein associations were sourced from StringDB and applied with an overlay of ASD/Epi risk genes from the SFARI, and EpilepsyGene databases. The colors indicate whether the proteins are implicated in ASD or epilepsy alone, or both. B. The same analysis was carried out for the $800 \mathrm{kDa}$ protein complex $(\mathrm{n}=4)$.

Figure 5. Immunoblots confirm the presence of several high risk ASD/Epi risk gene products in protein complexes that contain $\mathrm{KCC} 2$. A. $\mathrm{KCC} 2$ protein complexes were isolated from 
products

KCC2 and autism/epilepsy risk gene

forebrain plasma membrane fractions of 8-12-week-old mice, resolved by BN-PAGE and immunoblotted for selected high risk ASD/Epi risk gene products; ANK2, ANK3, CNTN1, ITPR1, NCKAP1, SCN2A, SHANK3, SPTAN1 and SPTBN1.

Figure 6. High risk ASD/Epi risk gene products that are in complex with $\mathrm{KCC2}$, colocalize with KCC2 in several neuronal cellular compartments. A. Primary cultured neurons from P1 pups were infected with CAMKII AAV-GFP at DIV 3 (to visualize cell morphology and to identify excitatory neurons) and fixed at DIV 21. The cells were immunostained for KCC2 and high risk ASD/Epi risk gene products; ANK2, ANK3, CNTN1, ITPR1, NCKAP1, SCN2A, SHANK3, SPTAN1 and SPTBN1 (n=3).

Figure 7. The total and plasma membrane expression levels of KCC2 and several associated ASD/Epi risk gene products are changed in FMR1 KO (FX) animals. A. Total forebrain lysates and plasma membrane lysates were resolved by SDS-PAGE and immunoblotted for selected high risk ASD/Epi risk gene product; ANK2, ANK3, CNTN1, ITPR1, NCKAP1, SCN2A, SHANK3, SPTAN1 and SPTBN1. B. The expression levels for each protein were quantified using densitometry and normalized to $\alpha$-Tubulin loading controls $(n=3)$ KCC2 ( $p=0.037)$, ANK3-190 $(\mathrm{p}=0.0014)$, CNTN1 $(\mathrm{p}=0.011)$, and ITPR1 $(\mathrm{p}=0.016)$ were significantly reduced in plasma membrane fractions.

Figure 8. KCC2 is aberrantly phosphorylated in FMR1 KO (FX) mice. A. KCC2 was isolated from plasma membrane fractions of mouse forebrain and resolved by SDS-PAGE. B. Bar graphs of high confidence phosphorylated peptides relative to total detected peptides in wild type and FMR1 KO mice. For bars where phosphorylation was detected, A scores are superimposed to express phosphoryation confidence levels. C. Diagram of high confidence KCC2 phosphorylation site positions. 
Figure 1.

a)
PM
b) Isolation

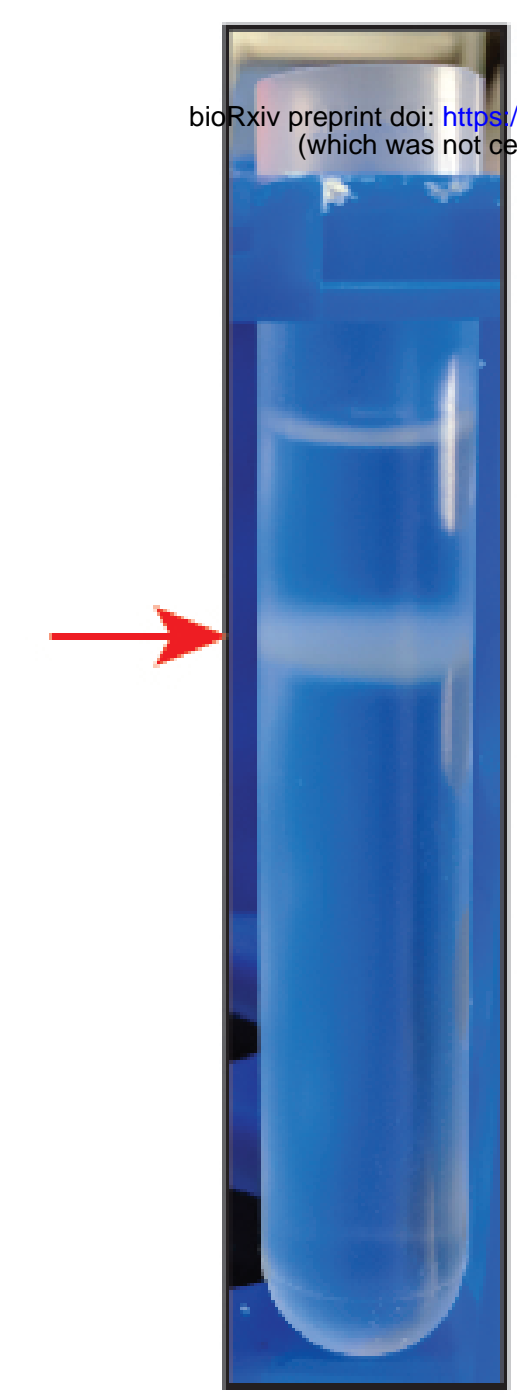

d)

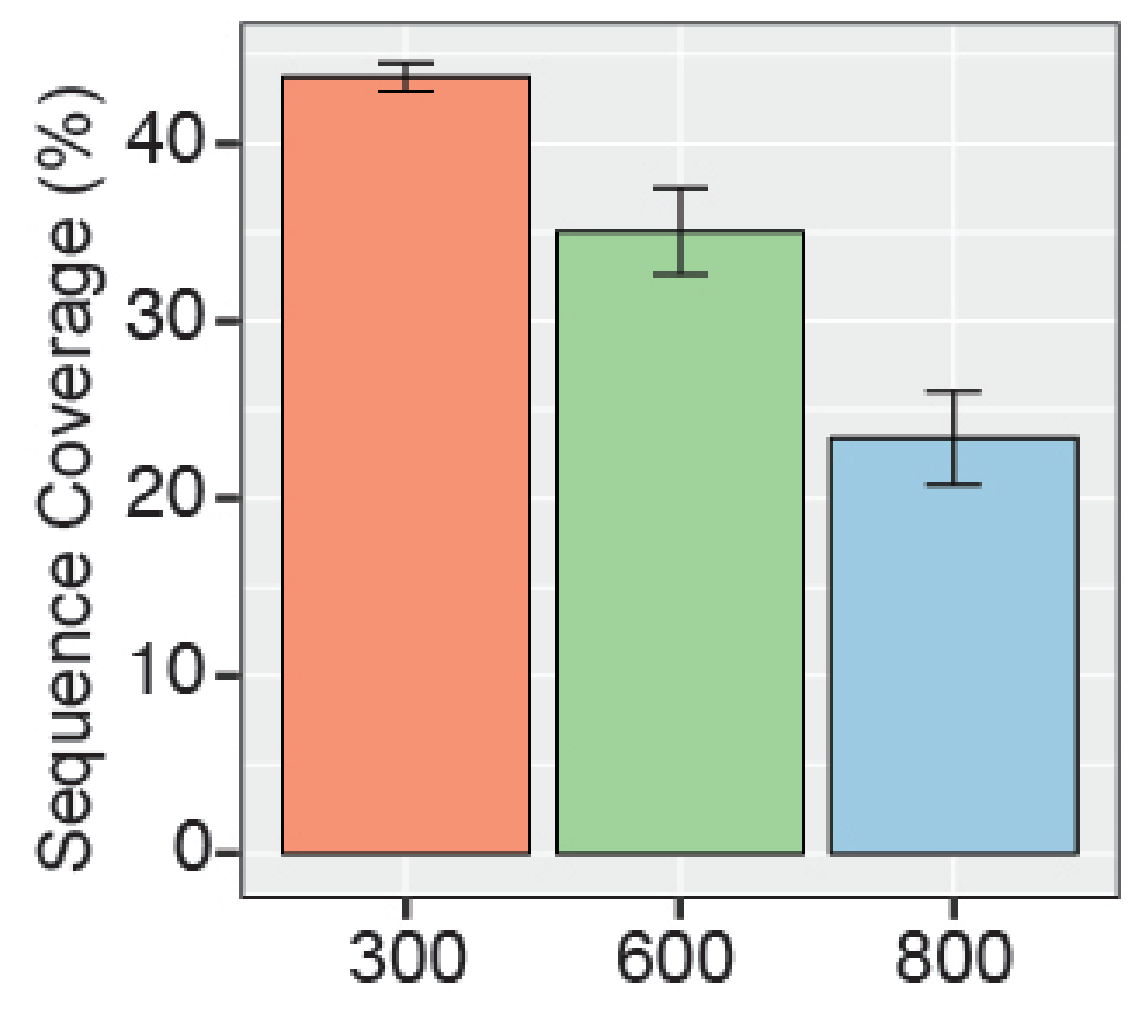

Molecular Weight (kDa) c)

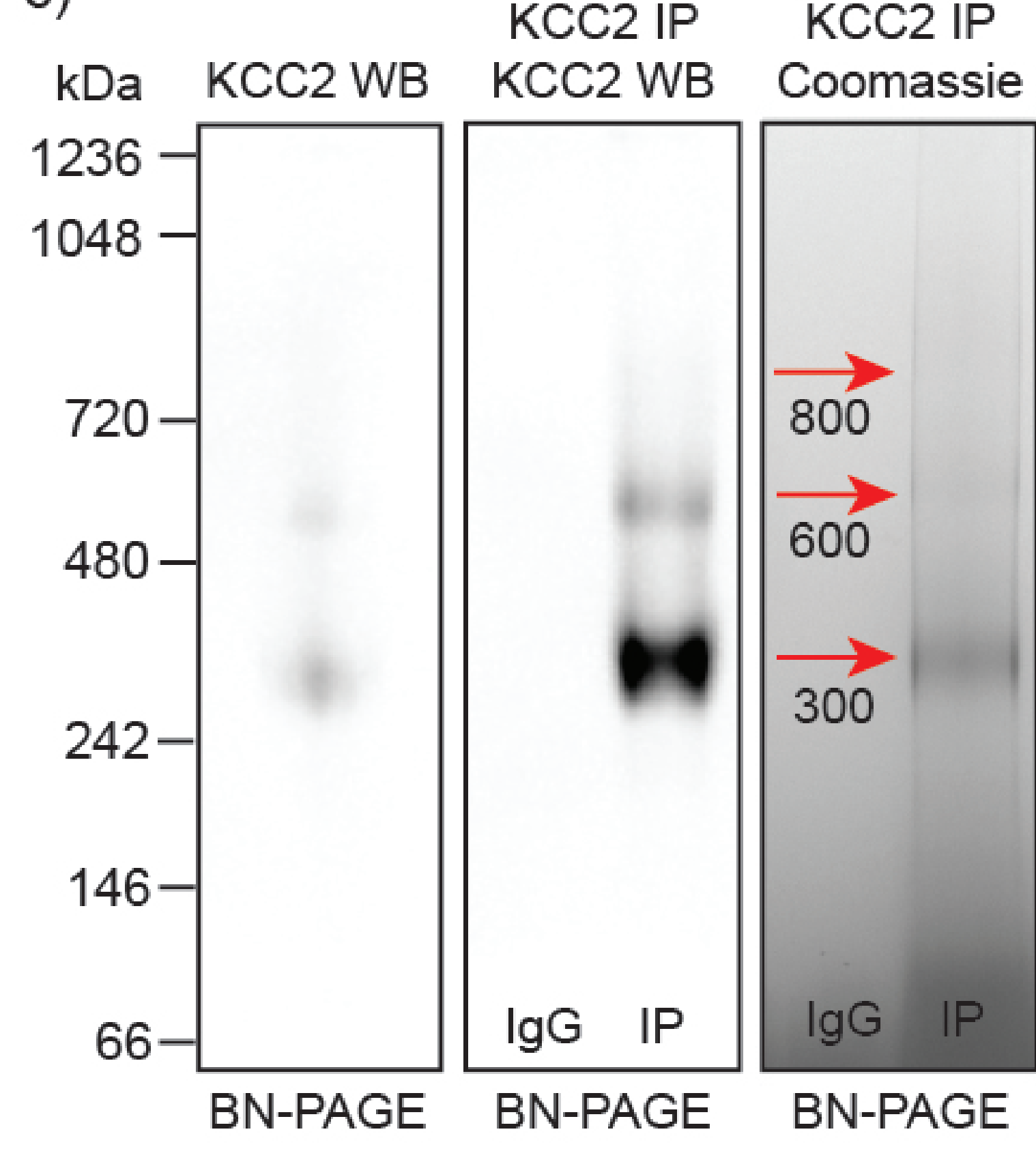

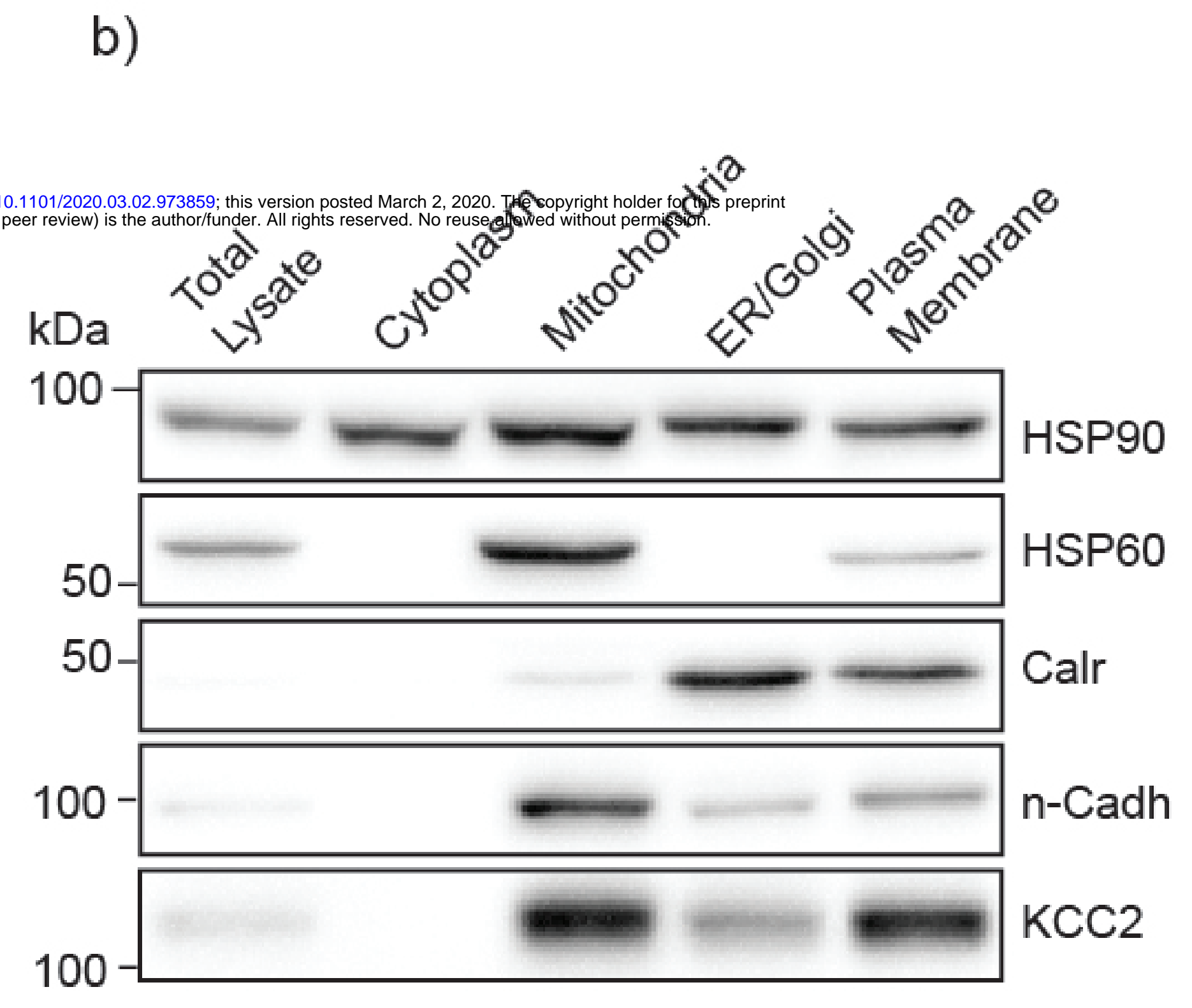

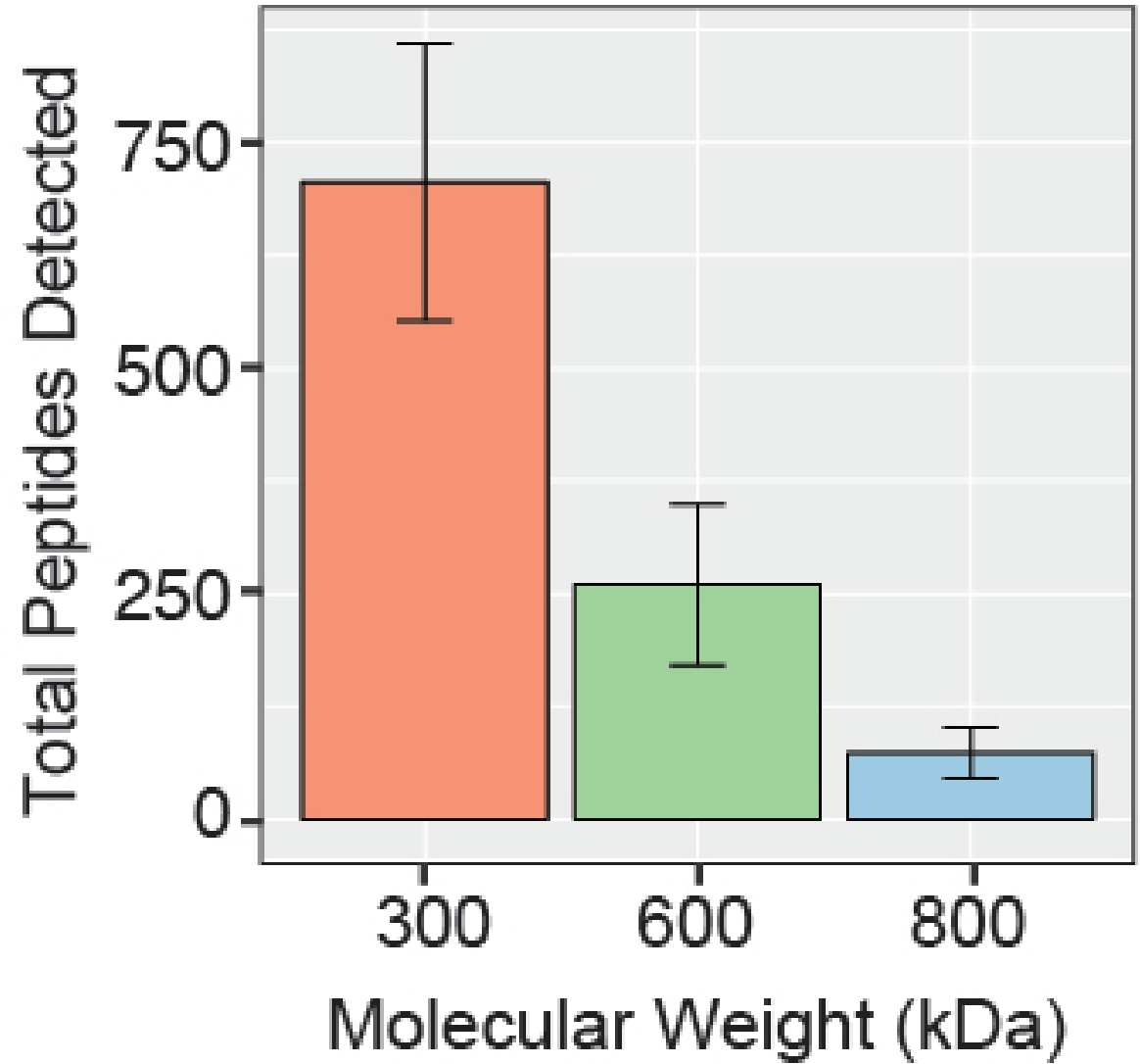


a)

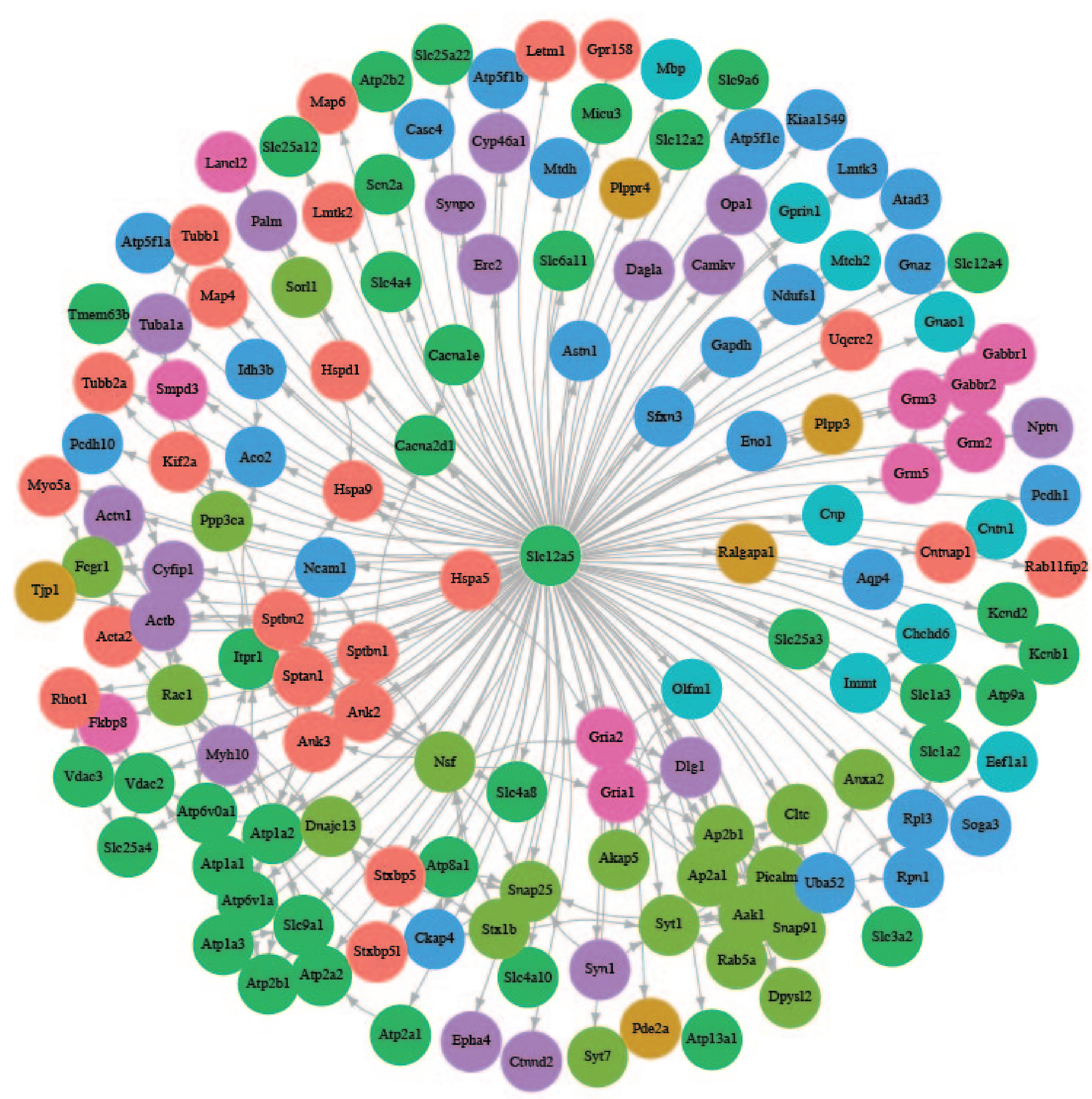

Whive preprint doi: https://doi.org/10.1101/2020.03.02.973859; this version posted March 2, 2020. The copyright holder for this preprin

b)

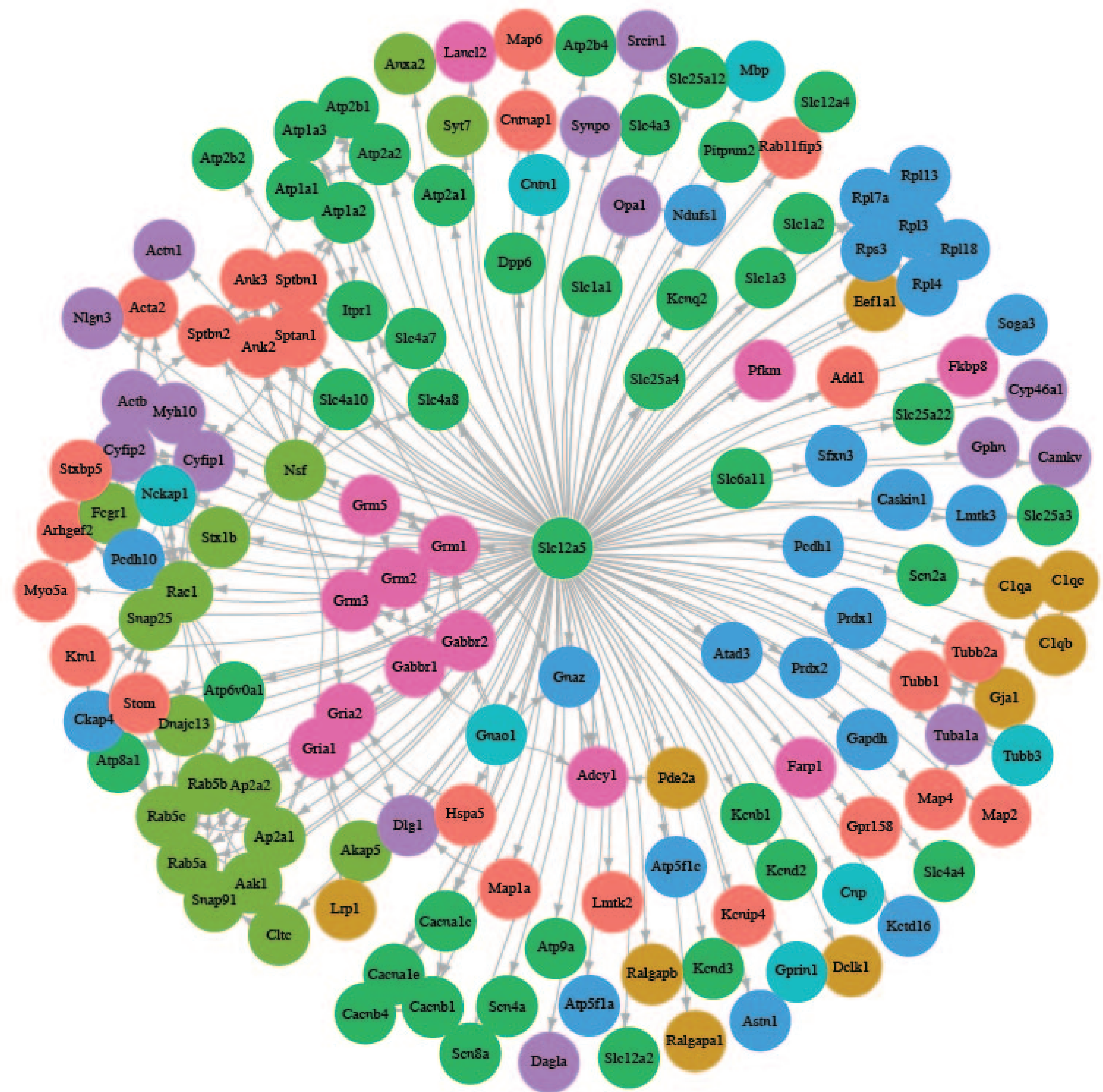

Ion Transporters

Cellular Localization

Development

Endocytosis

Membrane Organization

Synaptic Signaling

Synapse Organization

Other 
Figure 4.

a)

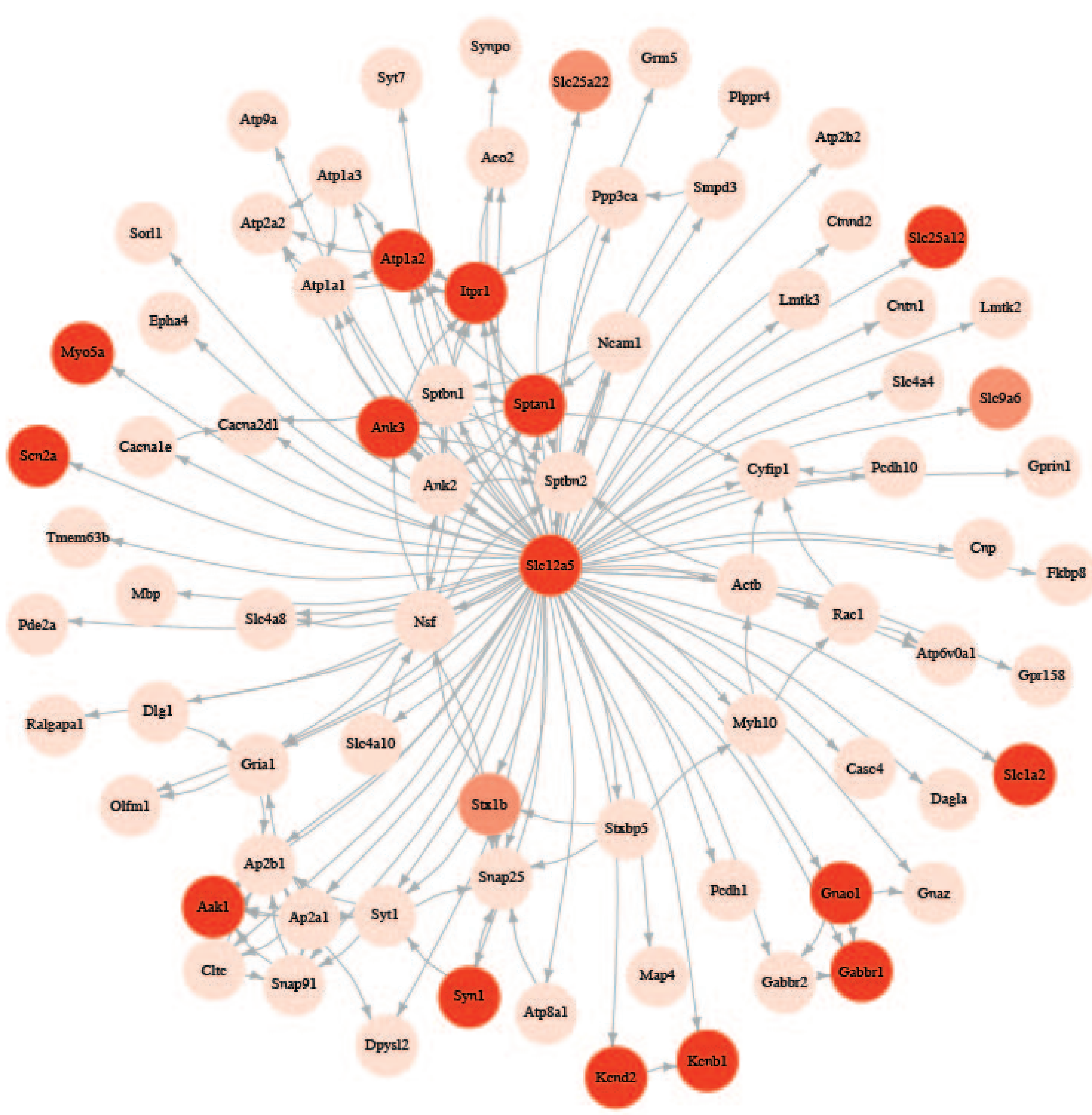

bioRxiv preprint doi: https:///doi.org/10.1101/2020.03.02.9738599: this version posted March 2, 2020. The copyright holder for this preprint
(which was not certified by peer review) is the authorffunder. Al rights reserved. No reuse allowed without permission.

b)

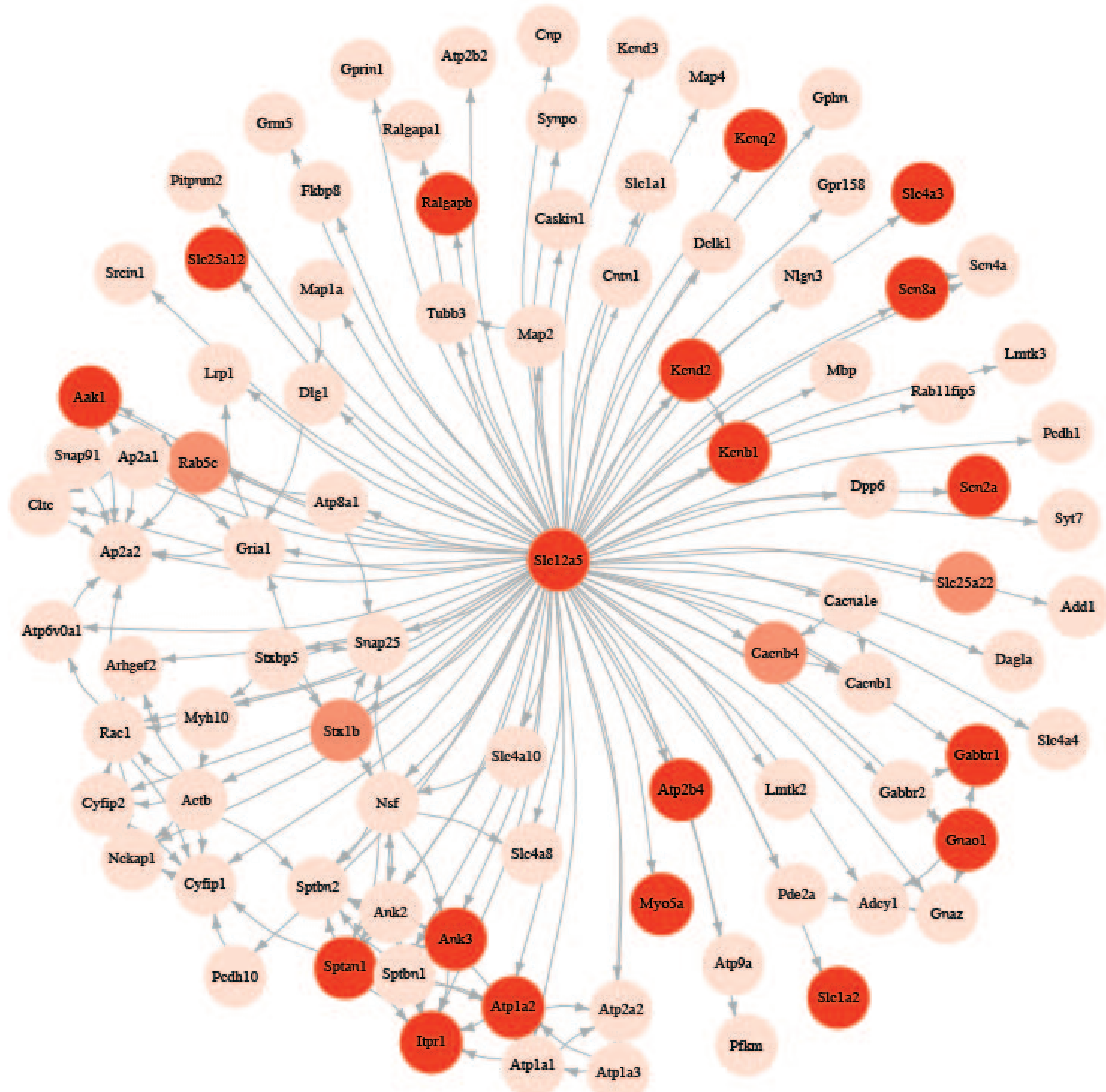

Implicated in ASD

Implicated in Epilepsy

Implicated in ASD and Epilepsy 

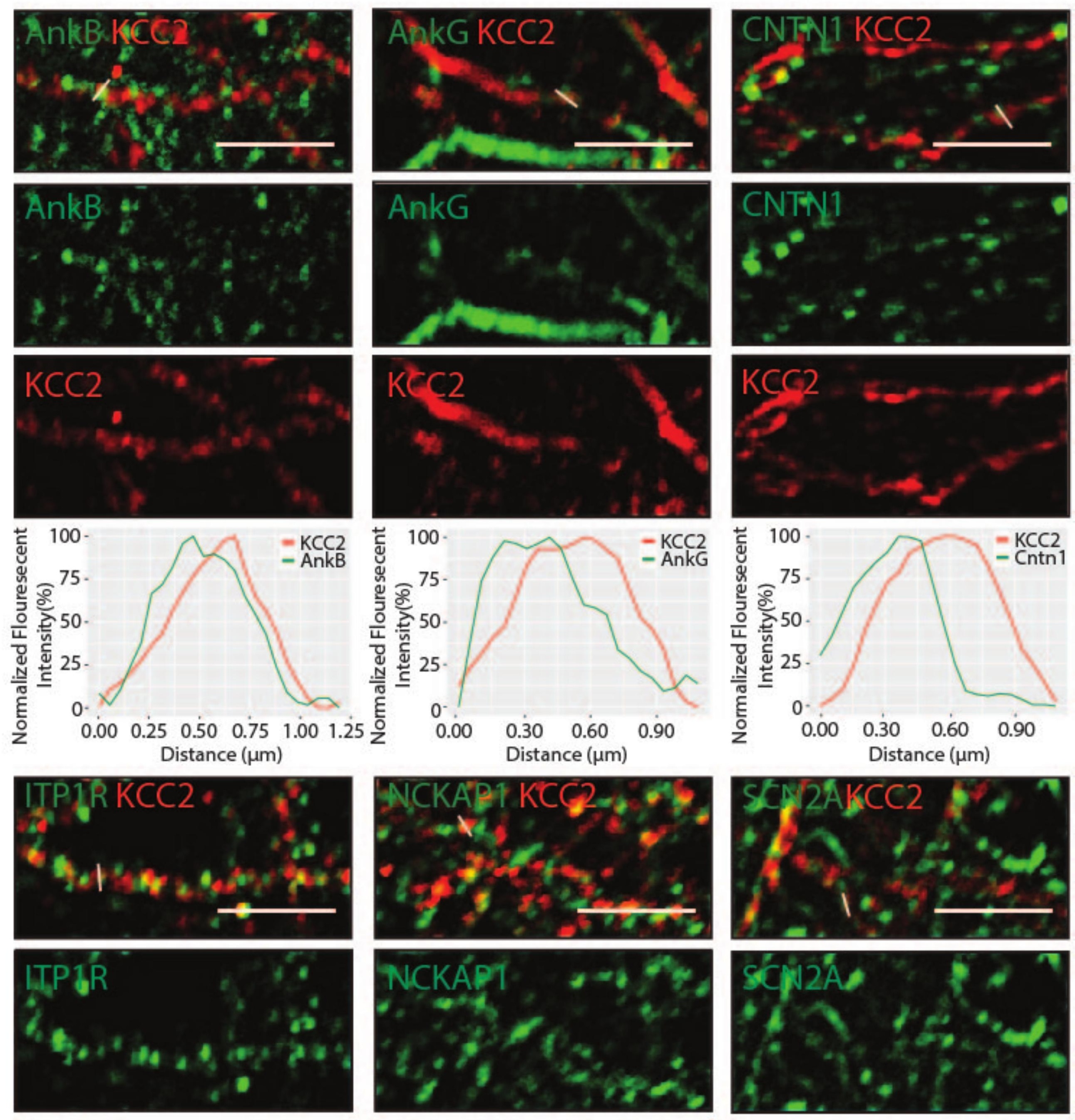

bioRxiv preprint doi: https://doi.c
(which was not certifie
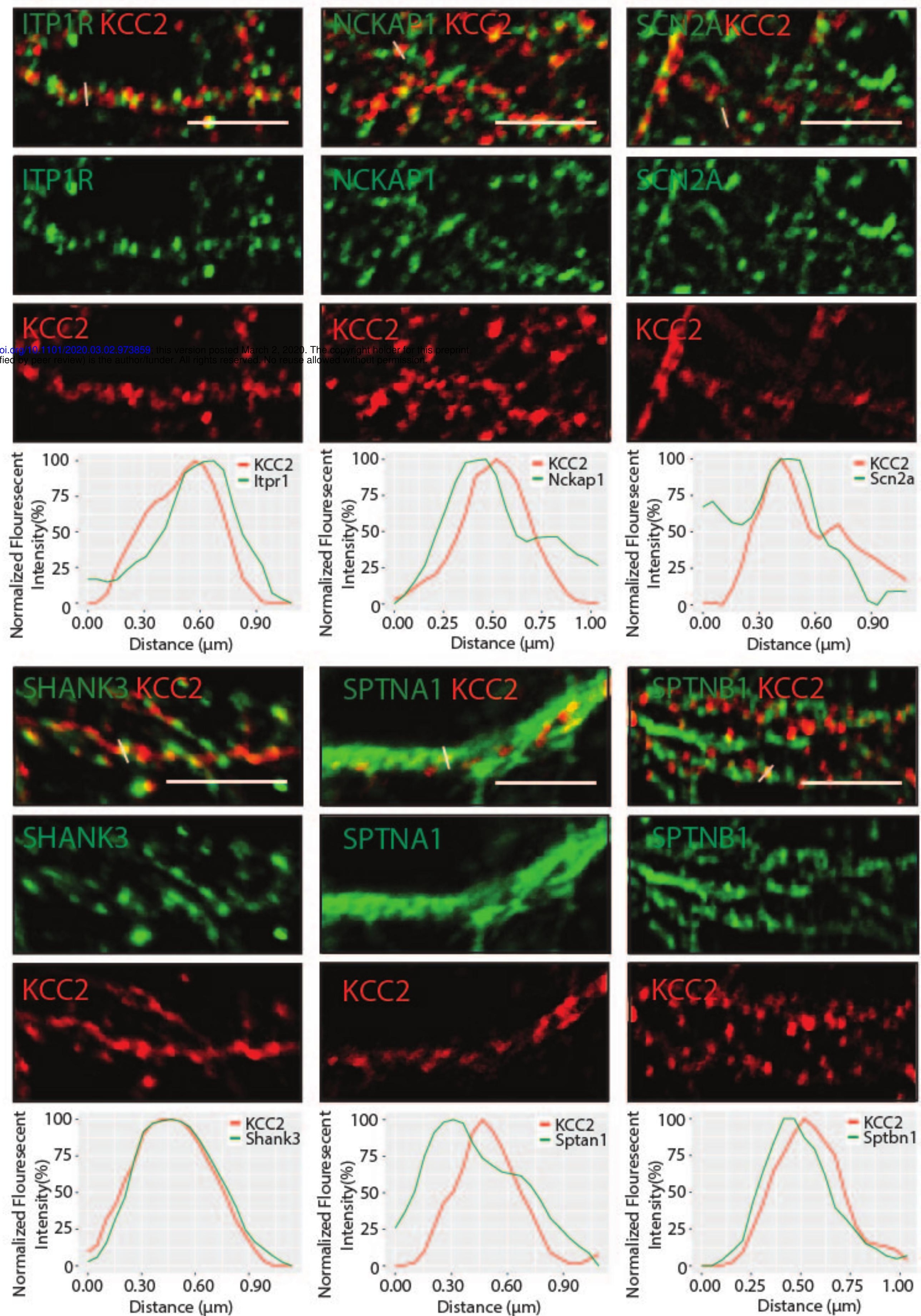
b) $\square$ TLWT $\square$ TLFX $\square$ PMWT $\square$ PMFX
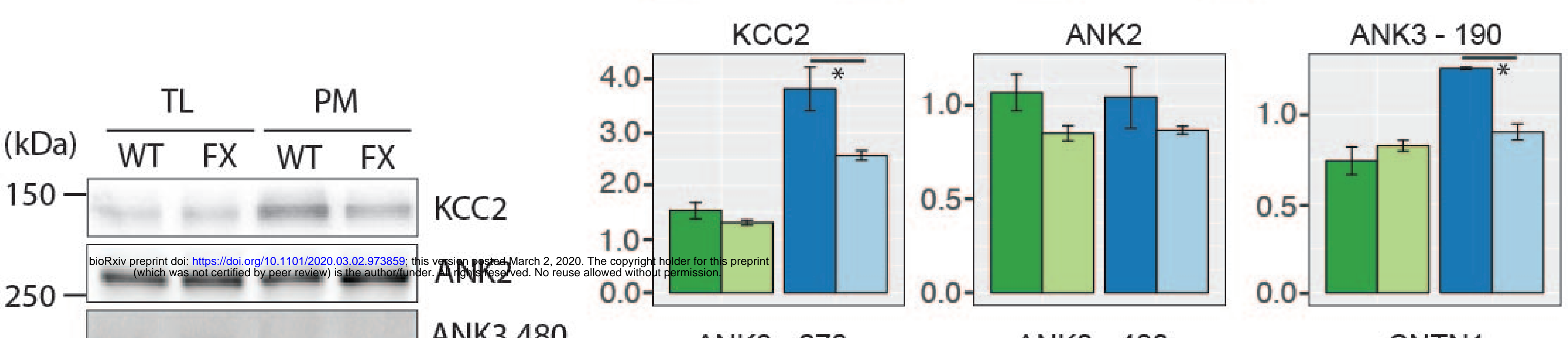

ANK3 480

ANK3 270
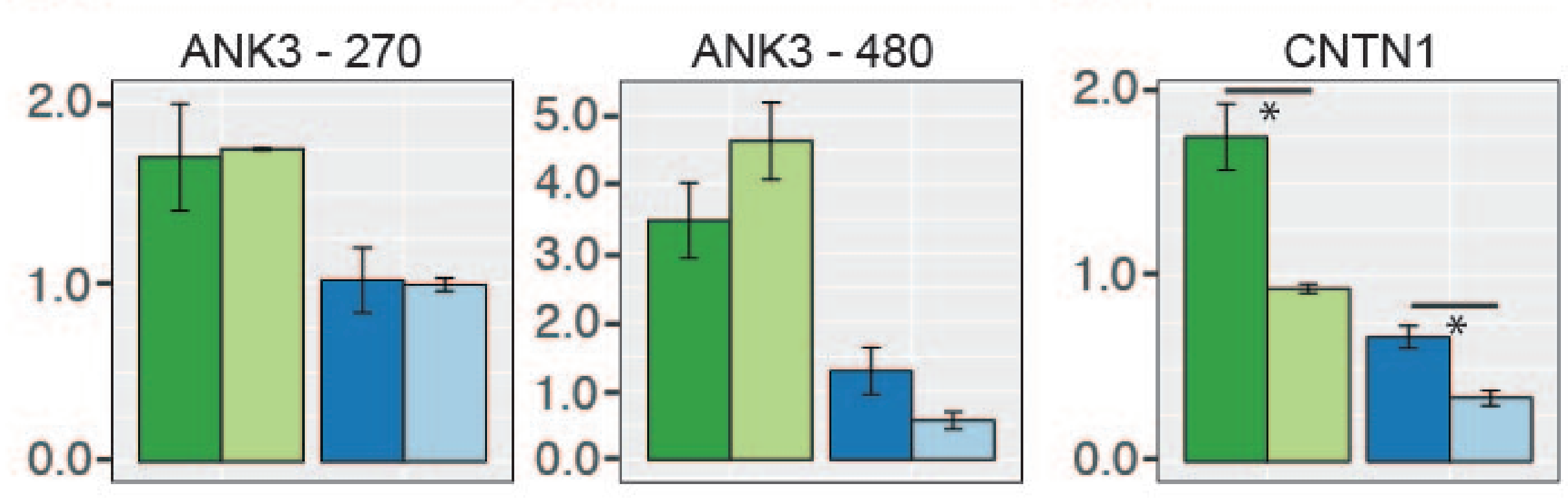

$-=$ CNTN1 $\because \ldots$ ITPRI

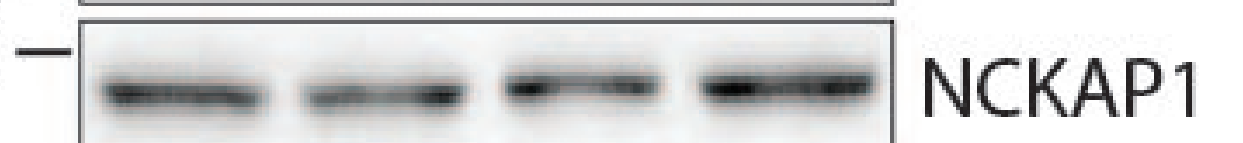

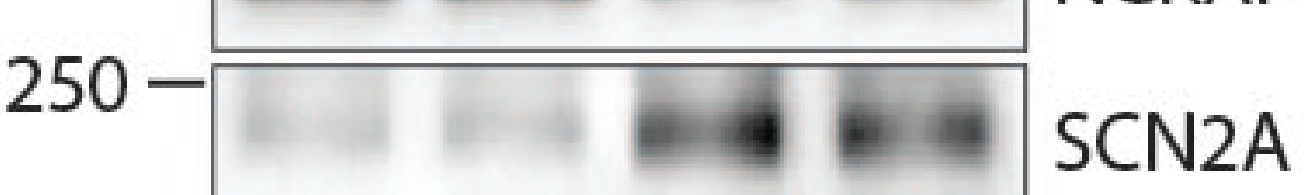

SHANK3

$250----$ SPTAN1

$250-=-\ldots$ SPTBN1

$50-\longrightarrow$ a-Tubuli
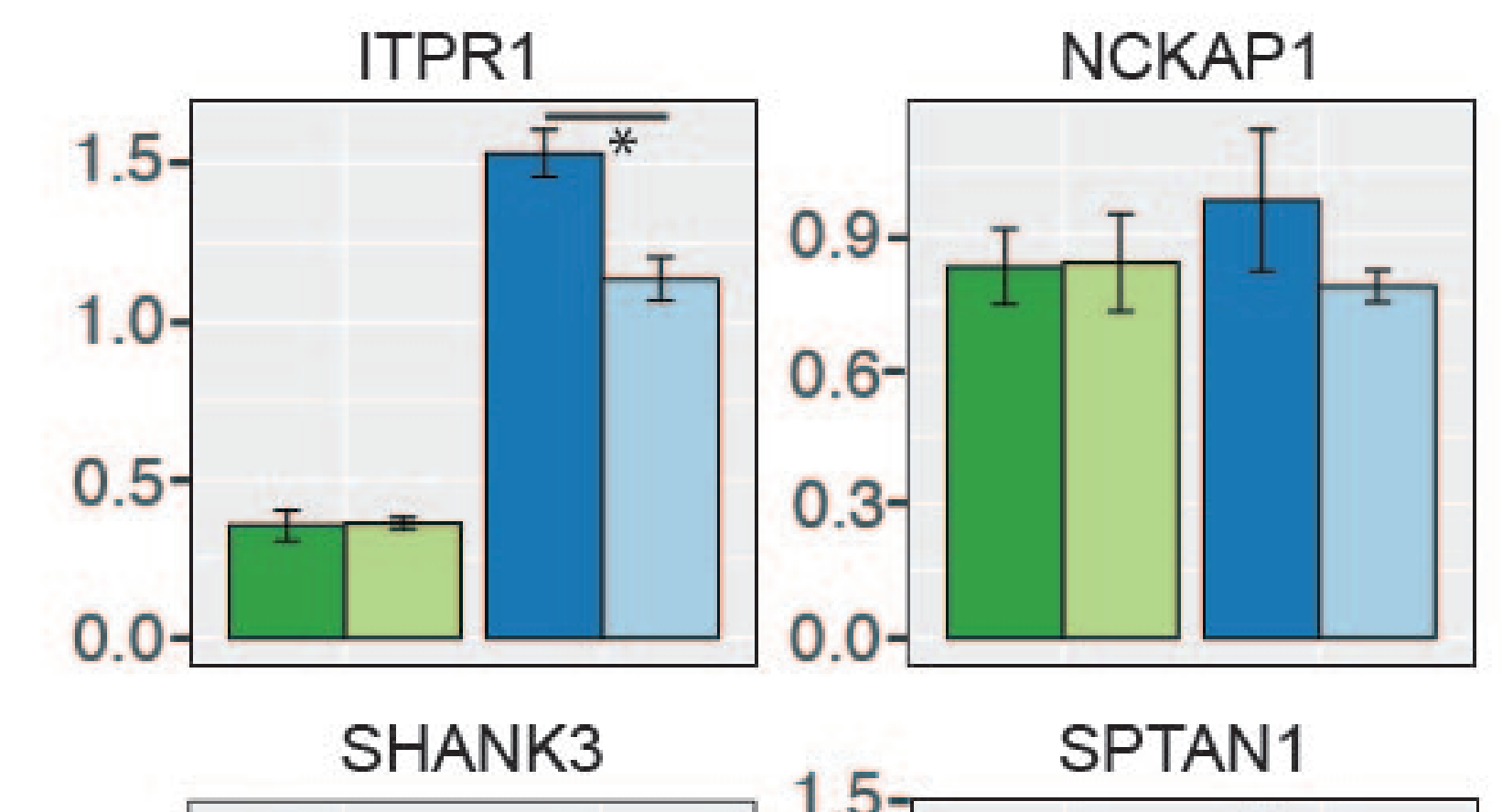

SCN2A
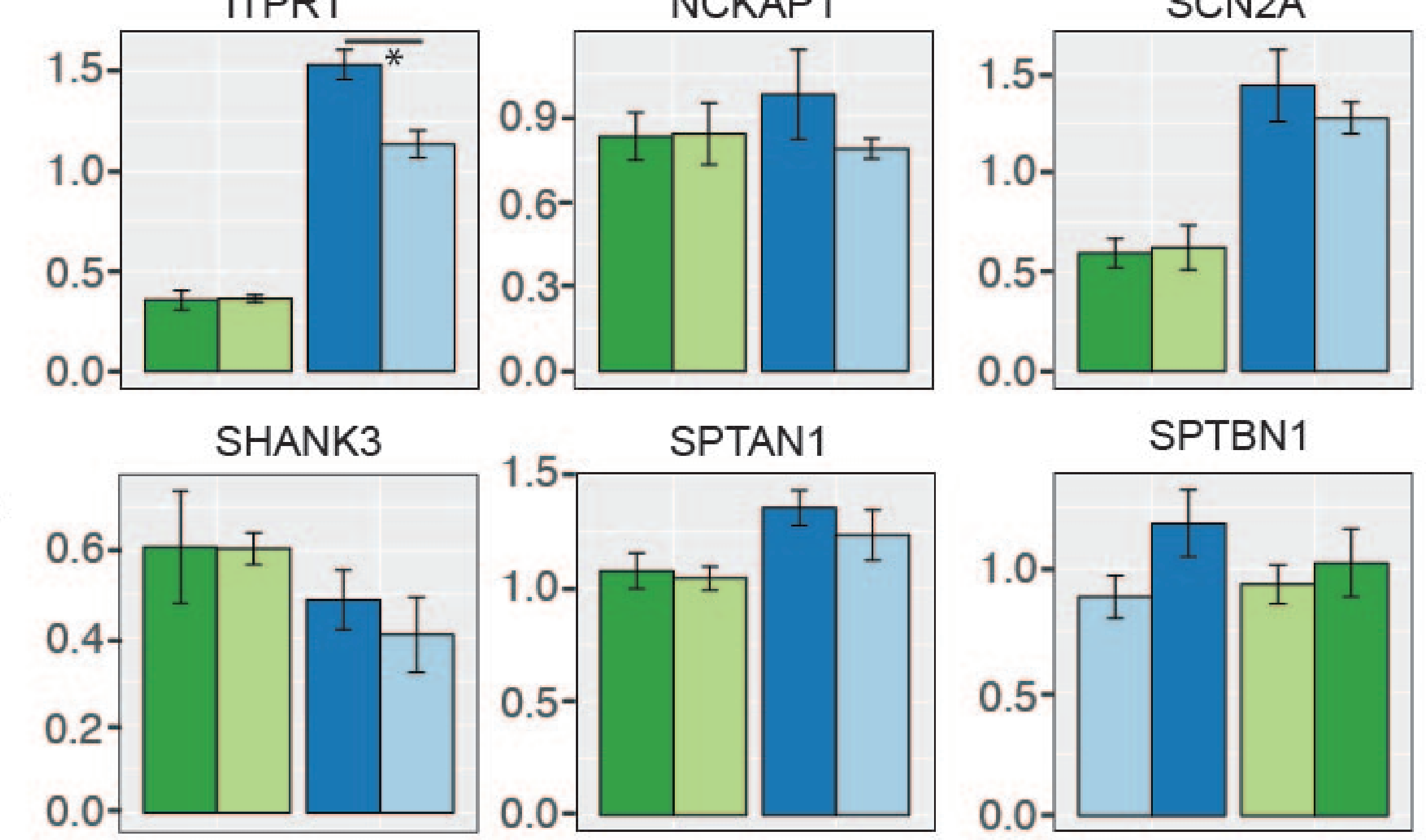
Figure 8.

a)

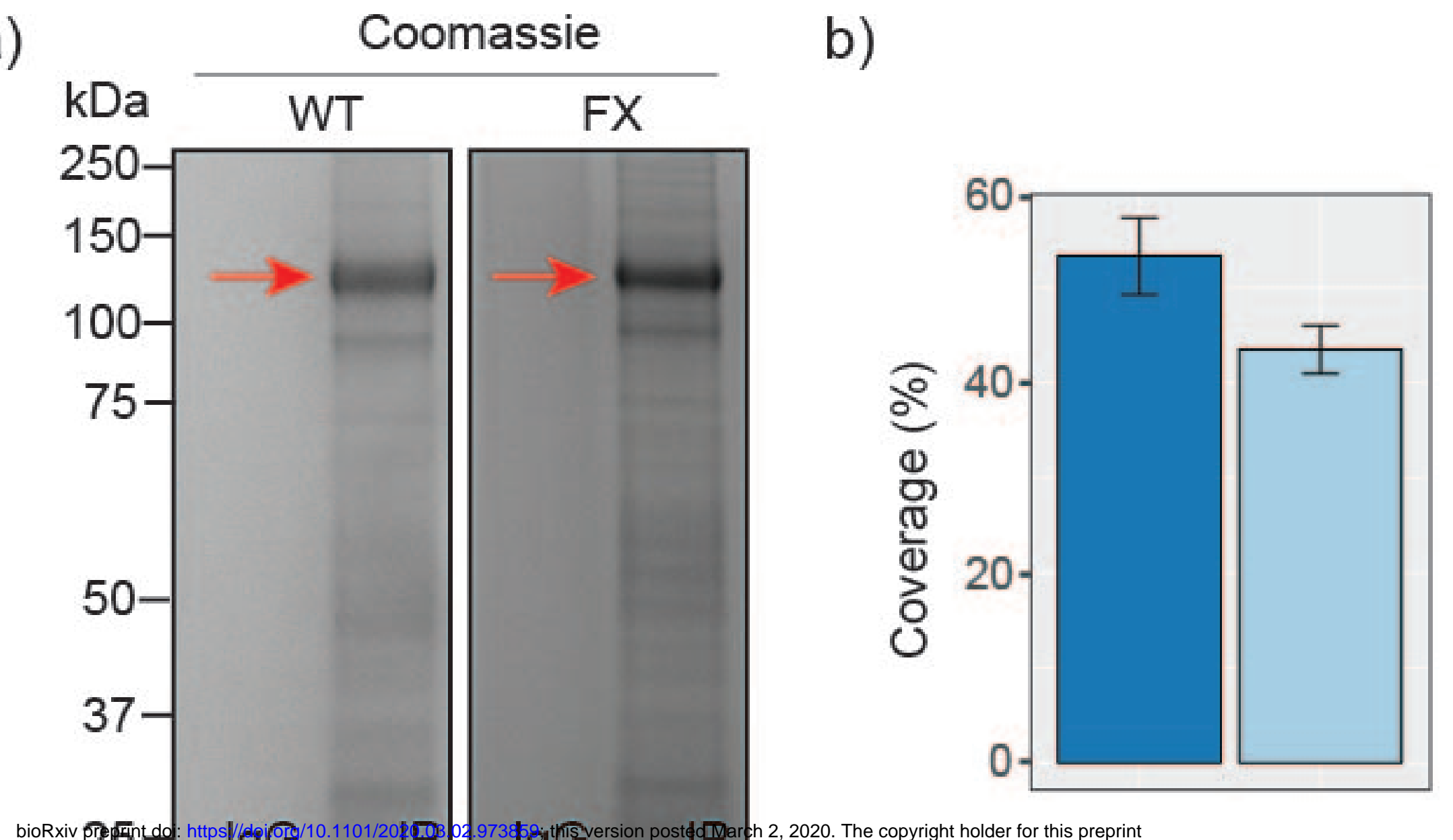

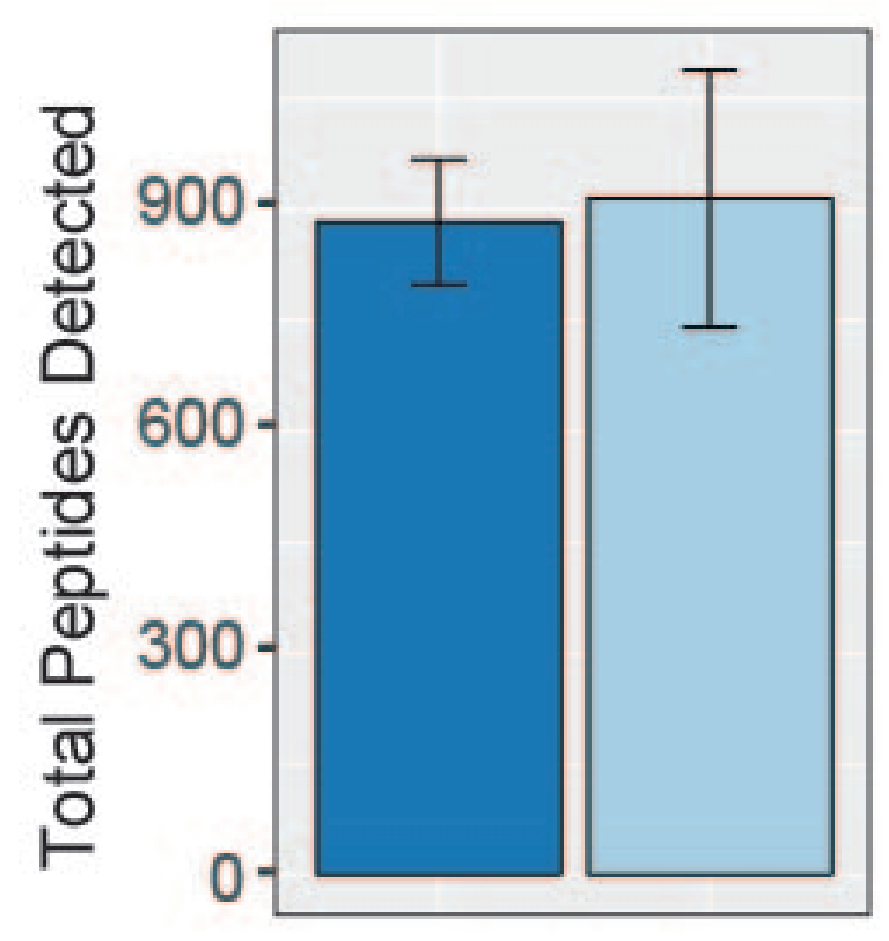

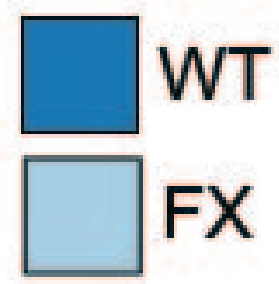

SDS-PAGE
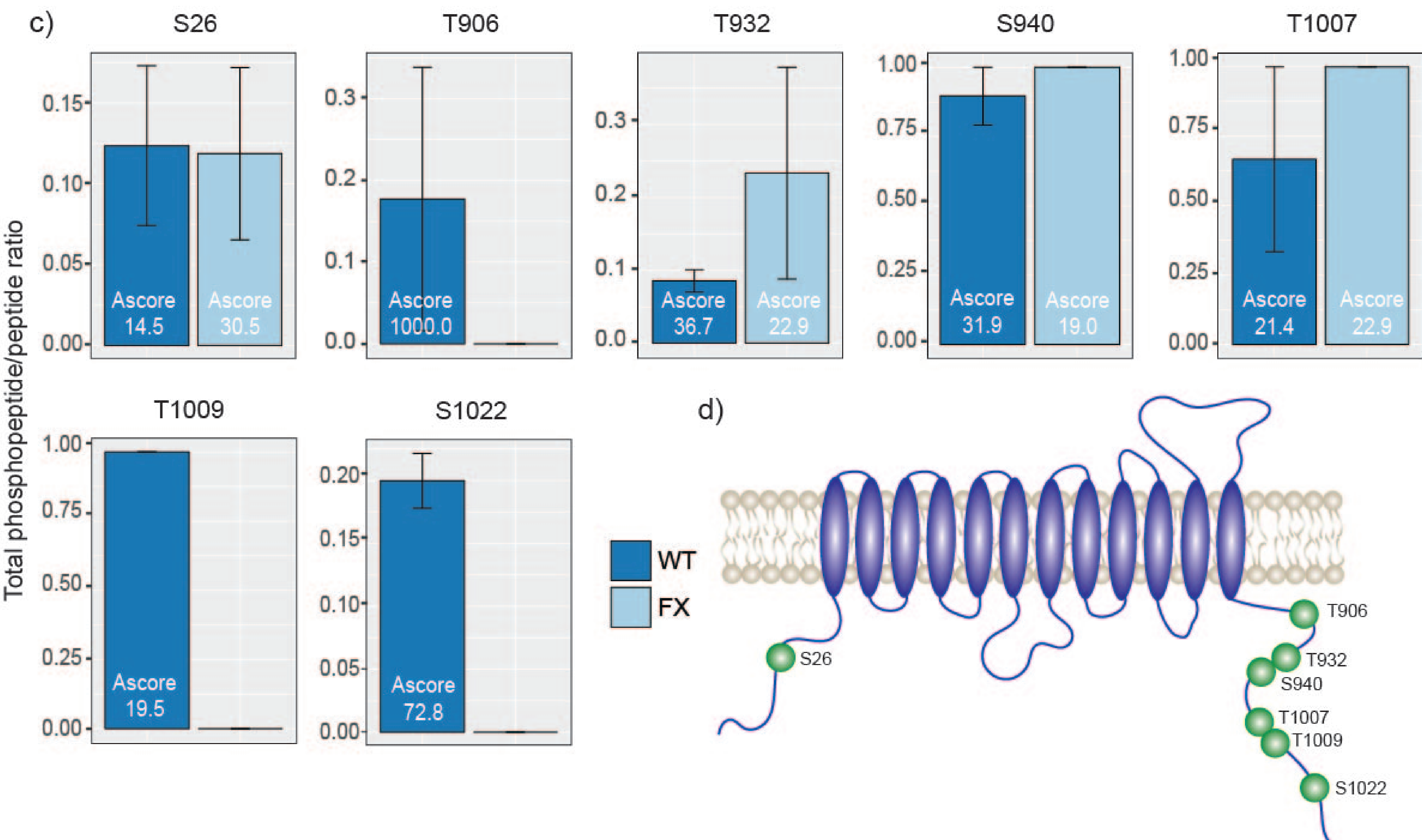